\title{
Mutations in CIC and IDH1 cooperatively regulate 2-hydroxyglutarate levels and cell clonogenicity
}

\author{
Suganthi Chittaranjann ${ }^{1}$, Susanna Chan ${ }^{1}$, Cindy Yang ${ }^{1}$, Kevin C. Yang ${ }^{1}$, Vincent \\ Chen $^{1}$, Annie Moradian ${ }^{1,2}$, Marlo Firme ${ }^{1}$, Jungeun Song ${ }^{1}$, Nancy E. Go ${ }^{1,3}$, Michael \\ D. Blough ${ }^{4,5,8}$, Jennifer A. Chan ${ }^{5,7,8}$, J. Gregory Cairncross ${ }^{4,5,8}$, Sharon M. Gorski ${ }^{1,3}$, \\ Gregg B. Morin ${ }^{1,9}$, Stephen Yip ${ }^{6}$ and Marco A. Marra ${ }^{1,9}$ \\ ${ }^{1}$ Canada's Michael Smith Genome Sciences Centre, BC Cancer Agency, Vancouver, BC, Canada \\ ${ }^{2}$ California Institute of Technology, Beckman Institute, Pasadena, CA, USA \\ ${ }^{3}$ Department of Molecular Biology and Biochemistry, Simon Fraser University, Burnaby, BC, Canada \\ ${ }^{4}$ Department of Clinical Neurosciences, University of Calgary, Calgary, AB, Canada \\ ${ }^{5}$ Southern Alberta Cancer Research Institute, University of Calgary, Calgary, AB, Canada \\ ${ }^{6}$ Department of Pathology \& Laboratory Medicine Vancouver General Hospital, Vancouver, BC, Canada \\ 7 Department of Pathology and Laboratory Medicine, University of Calgary, Calgary, AB, Canada \\ ${ }^{8}$ Clark H. Smith Brain Tumour Centre, University of Calgary, Calgary, AB, Canada \\ ${ }^{9}$ Department of Medical Genetics, University of British Columbia, Vancouver, BC, Canada \\ Correspondence to: Marco A. Marra, email: mmarra@bcgsc.ca
}

Keywords: CIC / IDH1 / ACLY / citrate / 2HG / Oligodendroglioma

Received: April 01,2014 Accepted: August 26, 2014 Published: August 27, 2014

This is an open-access article distributed under the terms of the Creative Commons Attribution License, which permits unrestricted use, distribution, and reproduction in any medium, provided the original author and source are credited.

\section{ABSTRACT}

The majority of oligodendrogliomas (ODGs) exhibit combined losses of chromosomes 1p and 19q and mutations of isocitrate dehydrogenase (IDH1-R132H or IDH2-R172K). Approximately 70\% of ODGs with 1p19q co-deletions harbor somatic mutations in the Capicua Transcriptional Repressor (CIC) gene on chromosome 19q13.2. Here we show that endogenous long (CIC-L) and short (CIC-S) CIC proteins are predominantly localized to the nucleus or cytoplasm, respectively. Cytoplasmic CIC-S is found in close proximity to the mitochondria. To study wild type and mutant CIC function and motivated by the paucity of 1p19q co-deleted ODG lines, we created HEK293 and HOG stable cell lines ectopically co-expressing CIC and IDH1. Non-mutant lines displayed increased clonogenicity, but cells co-expressing the mutant IDH1R132H with either CIC-S-R201W or -R1515H showed reduced clonogenicity in an additive manner, demonstrating cooperative effects in our assays. Expression of mutant CIC-R1515H increased cellular 2-Hydroxyglutarate (2HG) levels compared to wild type CIC in IDH1-R132H background. Levels of phosphorylated ATP-citrate Lyase (ACLY) were lower in cell lines expressing mutant CIC-S proteins compared to cells expressing wild type CIC-S, supporting a cytosolic citrate metabolism-related mechanism of reduced clonogenicity in our in vitro model systems. ACLY or phosphoACLY were similarly reduced in CIC-mutant 1p19q co-deleted oligodendroglioma patient samples.

\section{INTRODUCTION}

Oligodendrogliomas (ODG)s are a histologically, therapeutically and cytogenetically distinct subgroup of gliomas [1]. The majority of ODGs exhibit combined loss of chromosomes $1 p$ and $19 q$ and recurrent mutations of IDH1 or IDH2 (R132H or R172K respectively) [2]. Such ODGs are slow growing, respond well to chemotherapy and patients exhibit improved survival outcome compared to other gliomas that retain $1 \mathrm{p}[3,4]$. DNA sequencing of 
ODG tumour samples with $1 p$ and $19 q$ deletions identified somatic mutations in the gene $C I C[2,5]$ located on chromosome 19q13.2. CIC mutations affected 53-69\% of ODG cases, and included missense, nonsense, and out-offrame insertions and deletions [2, 5-7]. More than 25\% of the $C I C$ mutations were predicted to inactivate their encoded proteins [5]. Such inactivating mutation patterns are generally observed in tumour suppressor genes such as TP53 and FBXW7, but not in oncogenes [5]. Among the somatic mutations observed in $\mathrm{CIC}, 41 \%$ and $7 \%$ of the missense mutations were found in the CIC DNA-binding HMG domain and the Groucho protein-protein interaction domain, respectively $[2,5,7,8]$.

Somatic mutations were also observed in the gene encoding far upstream element (FUSE) binding protein 1 (FUBP1) on chromosome 1p31.1 [5] at a frequency (16\%) lower than CIC mutations. A recent study of 45 ODGs with $1 \mathrm{p} 19 \mathrm{q}$ co-deletions identified two hotspot point mutations ( -124 and -146 bp upstream from the ATG start site) in the promoter region of telomerase reverse transcriptase (TERT) [9] on chromosome 5p15.33, the catalytic subunit of the enzyme telomerase. These point mutations create a binding sequence for the ETS transcription factor, which can subsequently activate TERT transcription. Exactly how these mutations contribute to oligodendrogliomagenesis has yet to be determined.

CIC is well conserved across evolutionary boundaries $[10,11]$, and was first identified as a HMGbox repressor downstream of the RTK-Ras-Raf-MAPK cascade [12] in Drosophila. In addition to terminal and dorsoventral patterning [12, 13] and wing vein specification [14], CIC is involved in ommatidial cell proliferation [15]. During ommatidial development, activation of EGFR signaling and down regulation of CIC levels was required for promoting cell growth and cell proliferation. At least two main CIC protein isoforms, which differ in both size (short form, CIC-S; long form, CIC-L) and in their N-terminal regions, have been identified in Drosophila and mammals. Both CIC-S and CIC-L are highly conserved between mouse and human ( $>99 \%$ amino acid identity) $[10,11]$, with predicted lengths of 1,608 AA and 2,517 AA respectively.

Relatively few studies have addressed the role of $\mathrm{CIC}$ in human biology and disease. For example, CIC appears to repress the PEA3 family of ETS transcription factors in cancers. Rare cases of Ewing's sarcoma express a novel CIC-DUX4 fusion protein encoded by a recurrent chromosomal translocation $\mathrm{t}(4 ; 19)(\mathrm{q} 35 ; \mathrm{q} 13)$ [16]. This fusion protein activated transcription of the PEA3 family genes ERM/ETV5 and ETV1 and overexpression of PEA3 family proteins was associated with invasive and metastatic phenotypes in breast and gastric cancers and in rhabdomyosarcoma [17]. In HEK293 cells, ribosomal protein S6 kinase II (p90RSK) phosphorylated CIC and promoted the binding of phosphorylated CIC to 143-3 regulatory proteins [18]. This interaction reduced the binding of CIC to CIC binding "TGAATGAA" promoter sequences and reduced CIC repressor activity. The reduced binding of CIC correlated with increased expression of CIC targets in vitro, such as ETV5 [18]. Finally, association of wild type CIC with polyglutamineexpanded ATAXIN-1 results in neurotoxicity and contributes to spinocerebellar ataxia (SCA1) [10, 19]. An ATXN1-CIC protein complex showed enhanced transcriptional repressor activity compared to CIC alone [10] and reducing CIC levels rescued the Ataxia phenotype in mouse models period. Additional in vitro and in vivo studies in mammalian systems are now required to elucidate the cellular functions of both CIC mutant and wild type proteins.

Alterations in glycolysis and citrate metabolism contribute to the survival of cancer cells including gliomas [20-22]. In cancers cells, the citrate transporter SLC25A1 preferentially transports mitochondrial citrate produced by the TCA cycle to the cytosol, where citrate plays a central role in metabolism [23, 24]. Cytosolic citrate can be converted to oxaloacetate (OAA) and acetyl-CoA by the enzyme ATP-citrate lyase (ACLY) in an ATP dependent manner. Acetyl-CoA is required for de novo lipid synthesis and acetylation of histones in proliferating cancer cells [24, 25]. Cytosolic citrate is also converted into isocitrate by acotinase and then into $\alpha$-2-ketoglutarate (2KG) by IDH1 [24]. However, mutant variants of IDH1 (eg.R132H/C/S/ $\mathrm{L} / \mathrm{G} / \mathrm{V}$ ) exhibit a neomorphic function that converts $2 \mathrm{KG}$ to the oncometabolite (R)-2 hydroxyglutarate (2HG) [26, 27]. Intracellular levels of $2 \mathrm{HG}$ are high in cancer cells containing IDH mutations and are sufficient to promote cell transformation [28]. In gliomas, $2 \mathrm{HG}$ significantly decreased 5-hydroxymethylcytosine $(5 \mathrm{hmC})$, increased DNA methylation and reduced DNA de-methylation, ultimately leading to a $\mathrm{CpG}$ island methylator phenotype (CIMP) [29].

In 1p19q co-deleted ODG, CIC mutations co-occur with mutations in either IDH1 or IDH2 in approximately $53-69 \%$ of cases, but the functional consequences of this co-occurrence are unknown [2, 5-7]. Here we describe, for the first time, the sub-cellular localization of endogenous CIC isoforms in human cells, including ODG cells with $1 \mathrm{p} 19 \mathrm{q}$ co-deletions. Endogenous CIC-L was predominantly localized to the nucleus. Endogenous CIC-S was predominantly cytoplasmic, in close proximity to mitochondria, and formed complexes with ACLY which synthesizes acetyl-CoA in the cytosol. We show that cells expressing mutant CIC proteins had lower levels of active phosphorylated ACLY (pACLY) compared to cells expressing wild type CIC. Cells coexpressing mutant IDH1-R132H and mutant CIC-R1515H displayed increased $2 \mathrm{HG}$ levels compared to cells coexpressing mutant IDH1-R132H and wild type CIC. Cells expressing IDH1-R132H mutations exhibited reduced cell proliferation compared to cells expressing wild type IDH1 or cells co-expressing both wild type CIC and IDH1. 
Co-expression of mutant IDH1-R132H and wild type CIC partially rescued the reduction in cell proliferation. Co-expression of mutant CIC (-R1515H and -R201W) and mutant IDH1-R132H further reduced clonogenicity compared to cells expressing mutant IDH1-R132H. Our data provide the first insights into the localization and function of mammalian wild type CIC and the mutant CIC proteins found in ODGs (eg. CIC-R1515H and CICR201W) in wild type IDH1 and mutant IDH1-R132H backgrounds and allude to novel non-nuclear functions of CIC.

\section{RESULTS}

\section{Capicua isoforms localize to different cellular compartments in mammalian cells}

To further characterize the predominant endogenous CIC protein isoforms (CIC-L and CIC-S) in human cells
[2], we prepared whole cell lysates of human embryonic kidney cell line HEK-293A: (hereafter referred to as HEK) and detected CIC proteins using western blotting. Our analysis of primary amino acid sequences predicted that CIC-S and CIC-L were $164 \mathrm{KDa}$ and $259 \mathrm{KDa}$ in size. However, an anti-CIC antibody (Methods) consistently detected two major protein bands that migrated at approximately $230 \mathrm{KDa}$ and $400 \mathrm{KDa}$ (Figure 1A; Supplementary Figure S1). We occasionally detected a smaller isoform at $170 \mathrm{KDa}$ (Supplementary Figure S1) but did not study this minor isoform further due to its variable presence. To validate the CIC antibody, we knocked down CIC using three different siRNAs (Methods) and quantitated CIC proteins using western blots and densitometry. Compared to scramble siRNA controls, $C I C$-siRNA1 or $C I C$-siRNAs $1+2+3$ significantly reduced both $230 \mathrm{KDa}$ CIC-S and $400 \mathrm{KDa}$ CIC-L protein bands to approximately $15 \%$ and $45 \%$ of control levels respectively (Figure 1B). To confirm the migration of CIC-S and CIC-L at $230 \mathrm{KDa}$ and $400 \mathrm{KDa}$ on protein gels, we ectopically expressed N-terminally FLAG fused
A

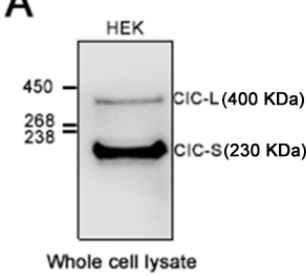

D

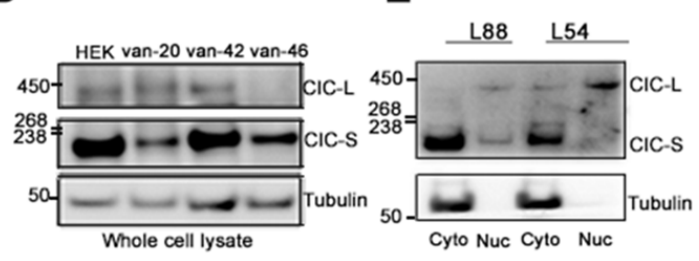

B

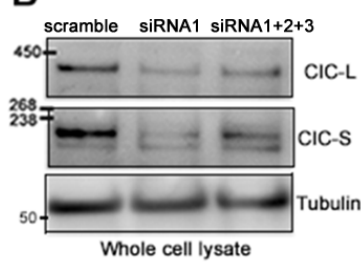

E
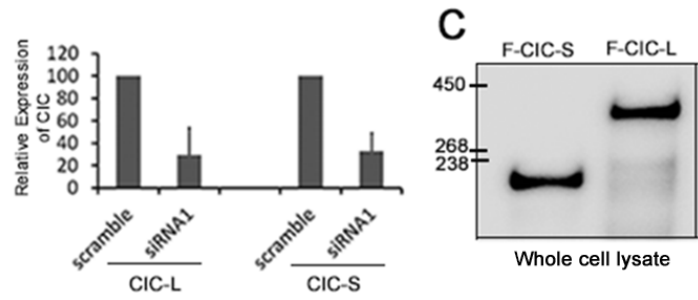

$\mathrm{F}$

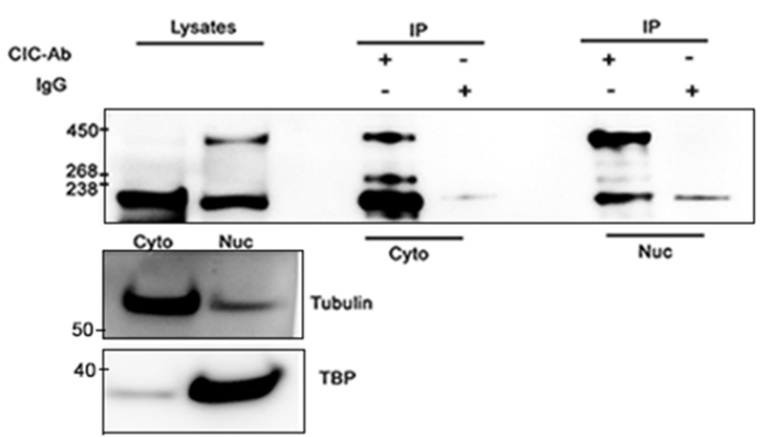

Figure 1: Subcellular localization of endogenous CIC isoforms in mammalian cells. A. Western blots using an anti-CIC antibody detected CIC isoforms CIC-L $(400 \mathrm{KDa})$ and CIC-S $(250 \mathrm{KDa})$ in HEK cells. B. HEK cells were transfected with a single siRNA (siRNA1) or a three siRNAs in combination (siRNA1+2+3) against CIC. Reductions in CIC-S and CIC-L were detected after $72 \mathrm{hrs}$ using western blots. Data are representative of three independent experiments. Changes in band intensities for CIC-L and CIC-S after siRNA1 treatment relative to scramble siRNA were quantified using densitometry and averaged over three independent experiments to generate the bar graph. C. N-terminal FLAG fusions with CIC-S (F-CIC-S) and CIC-L (F-CIC-L) were ectopically expressed in HEK cells and detected using a FLAG antibody. D. Whole lysate preparations of gliomas (van-20: Glioblastoma, no IDH1 mutation, no 1p19q co-deletion; van42 and van 46: oligodendroglioma, IDH1_R132H mutation, 1p19q loss) were probed for endogenous CIC expression using an anti-CIC antibody. E. Subcellular fractionations of ODG cell lines BT054 and BT088 were performed and cytoplasmic (Cyto) and nuclear (Nuc) fractions were isolated. Endogenous CIC isoforms were detected using western blots. Data shown are representative of three independent experiments. CIC-S is enriched in cytoplasmic fractions and CIC-L is enriched in nuclear fractions. F. Cytoplasmic (Cyto) and nuclear (Nuc) fractions were isolated from HEK cells and endogenous CIC isoforms were isolated using immunoprecipitations (IPs) with an antiCIC antibody. Subcellular localization of the isoforms was detected using a different anti-CIC antibody (by western blot analysis). Tubulin (Cyto) and TATA binding protein (TBP; Nuc) were detected as control proteins. Data shown are representative of at least three independent experiments. 
CIC-S (F-CIC-S) and CIC-L (F-CIC-L) proteins in HEK cells and detected CIC using a FLAG antibody and western blotting. F-CIC-S and F-CIC-L were detected at approximately $230 \mathrm{KDa}$ and $400 \mathrm{KDa}$ respectively (Figure 1C), confirming that CIC-S and CIC-L migrate at these molecular weights. We next explored whether these isoforms were present in gliomas. We isolated proteins from one non-ODG tumour with a $1 p$ deletion, two ODG tumors with 1p19q co-deletions, and cultured ODG cells BT054 (IDH1 ${ }^{+/ \mathrm{R}^{2} 2 \mathrm{H}} / \mathrm{CIC}^{+/-)}$and BT088 (IDH1 ${ }^{+/+} / \mathrm{CIC}^{\mathrm{R} 1515 \mathrm{H} /-)}$ [30], both containing 1p19q co-deletions. We detected the CIC-S isoform in all samples and the CIC-L isoform in two of three glioma tumor samples and in both ODG cell lines, indicating CIC isoforms of the expected size are present in glioma cells (Figure 1D-E, Supplementary Figure S1).

To determine the subcellular localization of endogenous CIC-S and CIC-L isoforms in HEK cells, we fractionated cells, purified cytoplasmic and nuclear fractions, and detected proteins that were enriched in these fractions (Methods). To assess the distribution of CIC-S and CIC-L, we immunoprecipitated (IP) CIC proteins

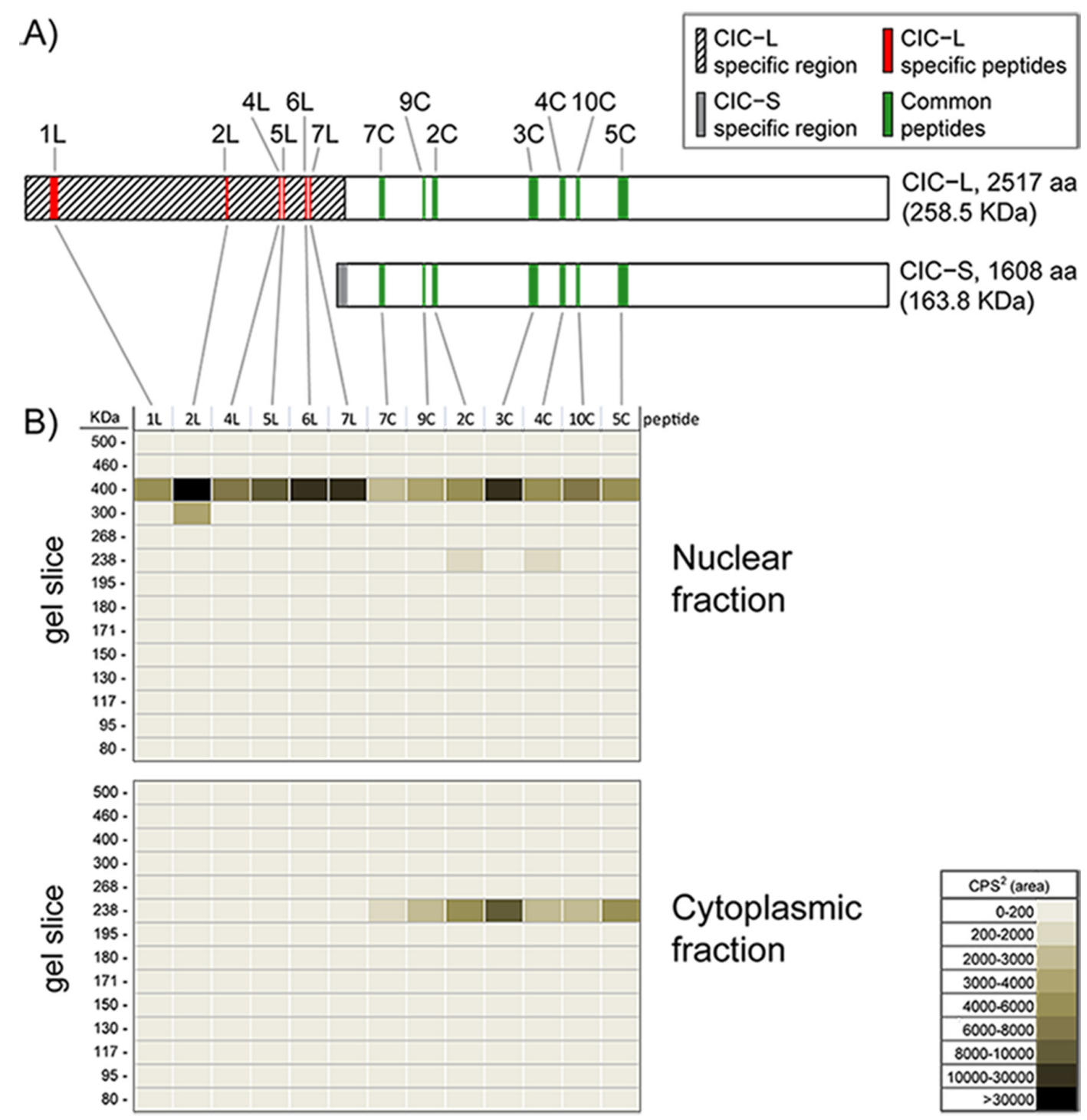

Figure 2: Mass spectrometry analysis confirms the localization of CIC-L to nuclei and CIC-S to the cytoplasm. A. Shown are the locations of the CIC peptides used to monitor the subcellular location of CIC by Multiple Reaction Monitoring (MRM) MS assays. A protein alignment cartoon shows the positions of the measured peptides specific for CIC-L (1L-7L; red) and the measured peptides common for both isoforms (2C-10C; green), see Supplementary Figure 2 for the sequence of the peptides. CIC-L and CIC-S specific regions are indicated in hatched and grey, respectively. Unfilled regions are common to both isoforms. B. Nuclear and cytoplasmic fractions were isolated from HEK cells and CIC isoforms were immunoprecipitated using an anti-CIC antibody. Immunoprecipitates were run on a protein gel and proteins were isolated from 14 different slices of the gel in the $80-500 \mathrm{KDa}$ region. Isolated proteins were used to detect peptides specific to CIC isoforms by MRM-MS. Peptides from each slice were measured. The peptide ion densities for the peptides are shown as a heat map for nuclear and cytoplasmic fractions (summed areas of each peptide transition peak, as counts per second ${ }^{2}\left(\mathrm{cps}^{2}\right)$ ). The data are representative of two independent trials. 
from cytoplasmic and nuclear fractions and analyzed the IP samples using western blots. In fractionated samples, CIC-S at $230 \mathrm{KDa}$ and CIC-L at $400 \mathrm{KDa}$ were enriched in the cytoplasmic $(59+/ 5 \%)$ and nuclear fractions $(89+/-$ $5 \%$ ), respectively (Figure 1F). In ODG lines BT054 and BT088, CIC-S and CIC-L were also predominantly observed in the cytoplasmic and nuclear fractions, respectively (Figure 1E).

To confirm the subcellular localization of CIC isoforms, we designed Multiple Reaction Monitoring (MRM) mass spectrometry (MS) assays for 10 peptides common to both isoforms and 9 peptides unique to the CIC-L isoform only (Figure 2A, Supplementary Figure S2). CIC protein IPs from cytoplasmic and nuclear fractions were separated on Tris-Acetate gels, and CIC peptide levels were measured in 14 gel slices spanning the 80-500 KDa range (Methods). In the nuclear fraction, $6 / 9$ peptides unique to $\mathrm{CIC}-\mathrm{L}$ and $7 / 10$ peptides common to both isoforms were detected only at $400 \mathrm{KDa}$ (Figure 2B), suggesting these peptides originated from the CIC-L isoform. In the cytoplasmic fraction at $230 \mathrm{KDa}$, we detected $7 / 10$ peptides common to both isoforms but no peptides unique to CIC-L were observed. These data are consistent with the notion that the peptides detected at $230 \mathrm{KDa}$ in the cytoplasmic fraction originated from the CIC-S isoform (Figure 2C). Taken together, these results confirmed that the proteins we detected at 230 and $400 \mathrm{KDa}$ were indeed CIC proteins, and that CIC-S is predominantly localized to the cytoplasm, while CIC-L is predominantly localized to the nucleus.

\section{Cytoplasmic CIC-S is localized to mitochondria}

During terminal and dorsoventral patterning of Drosophila embryos, CIC acts as a transcriptional repressor [12], yet in our standard culture conditions (Methods), $\sim 59 \%$ of CIC-S was found in the cytoplasm. This indicated to us the potential for CIC functions beyond transcriptional regulation. To further explore the localization of CIC-S, we detected cytoplasmic CIC using immunofluorescence (IF). We visualized CIC in HEK, MDA-MB-231 (breast carcinoma), C643 (thyroid carcinoma), H522 (lung carcinoma), and HeLa (ovarian carcinoma) cells using an anti-CIC antibody that can detect both CIC-S and CIC-L. Consistent with our nuclear and cytoplasmic fractionation studies, we observed $\mathrm{CIC}$ in both the nucleus and cytoplasm (Figure 3A). An unexpected observation was that cytoplasmic CIC signal was concentrated in puncta apparently close to mitochondria (representative images in Figure 3A).

To determine whether CIC was localized to mitochondria, we examined subcellular fractions of HEK cells enriched for cytoplasmic organelles (includes mitochondria; hereafter referred to as the mitochondrial fraction) or non-organelle cytosolic material. Control proteins ATP5A (mitochondrial) and tubulin (cytosolic) were predominantly in the mitochondrial fraction and cytosolic fractions, respectively, as expected (Figure 3B). The CIC-S form was consistently observed in both cytosolic and mitochondrial fractions (Figure $3 \mathrm{~B}$ ) and CIC-S was also detected in the mitochondrial (Figure 3C) fractions in other carcinoma cell lines.

To explore the nature of the CIC-S association with mitochondria, we isolated the mitochondrial fraction from HEK cells and subjected it to increasing concentrations of Proteinase $\mathrm{K}(0-15 \mu \mathrm{g} / \mathrm{ml})$ under isotonic conditions. Under these conditions, Proteinase $\mathrm{K}$ digests proteins exterior to the mitochondrial outer membrane. However, proteins embedded within the outer membrane and proteins located inside the membrane are protected from digestion. Mitochondrial proteins ATP5A (matrix), VDAC (embedded in the outer membrane), TOMM20 (translocase located outside of outer mitochondrial membrane) and RHAMM/HMMR, a protein loosely bound to mitochondria [31], served as controls. While mitochondrial proteins ATP5A and VDAC were protected from Proteinase $\mathrm{K}$ treatment at $15 \mu \mathrm{g} / \mathrm{ml}$, CIC-S, TOMM20 and RHAMM proteins were not protected (Figure 3D), indicating that CIC-S was most likely localized outside the mitochondrial outer membrane. To confirm that CIC-S was located exterior to the outer membrane of mitochondria and not embedded in the outer membrane, we used carbonate to solubilize proteins that are not embedded in the outer or inner membrane of mitochondria [31]. We treated the mitochondrial fraction from HEK cells with carbonate buffer (Methods) and detected CIC-S using western blots. As shown in Figure 3E, CIC-S and matrix protein ATP5A solubilized in the carbonate buffer and VDAC remained in the pellet containing mitochondrial membrane. Our result indicates that CIC is not embedded in the mitochondrial membrane but may instead be loosely associated with the mitochondrial membrane (Figure 3E). These findings are consistent with the notion that in mammalian cells, endogenous CIC-S is located very near or perhaps on the surface of mitochondria.

We next sought to determine the subcellular localization of both wild type and mutant endogenous CIC in ODG cell lines (BT054 and BT088) that carried 1p19q co-deletions in different IDH1 genetic backgrounds. While BT054 carries mutant IDH1 (R132H) and wild type CIC alleles, BT088 lacks mutant $I D H 1$ but carries a mutant CIC allele, encoding $\mathrm{R} 1515 \mathrm{H}$ in the protein-protein interaction domain, and no wild type $C I C$ allele $[2,30]$. We performed immunofluorescence (IF) experiments using an anti-CIC antibody that recognized both wild type and mutant CIC and an antibody that recognizes the mitochondrial protein ATAD3A [32]. Cytoplasmic CIC appeared to be adjacent to mitochondria in both BT054 and BT088 ODG cell lines (Figure 4A).

To determine whether wild type and mutant CIC-S were detected in the mitochondrial fraction in ODG cells, 
we isolated cytosolic and mitochondrial fractions of both BT054 and BT088 and detected CIC using western blots. In both ODG cell lines, CIC-S was detected in both cytosolic and mitochondrial fractions (Figure 4B). Compared to wild type CIC in BT054, levels of CIC$\mathrm{R} 1515 \mathrm{H}$ in BT088 were observed at higher levels in both fractions, indicating CIC-R $1515 \mathrm{H}$ is stable and that the mutation did not affect subcellular distribution between cytosolic and mitochondrial fractions.

\section{Expressions of both CIC and IDH mutant cooperatively increased $2 \mathrm{HG}$ production in HEK293 cells}

In our previous study [2], 69\% of ODGs with $1 \mathrm{p} 19 \mathrm{q}$ co-deletions carried mutations in both the $I D H$ and $C I C$ genes. Since mutations in IDH1 and IDH2 increase the production of $2 \mathrm{HG}$ [26] and endogenous CIC-S was observed close to mitochondria, we hypothesized that

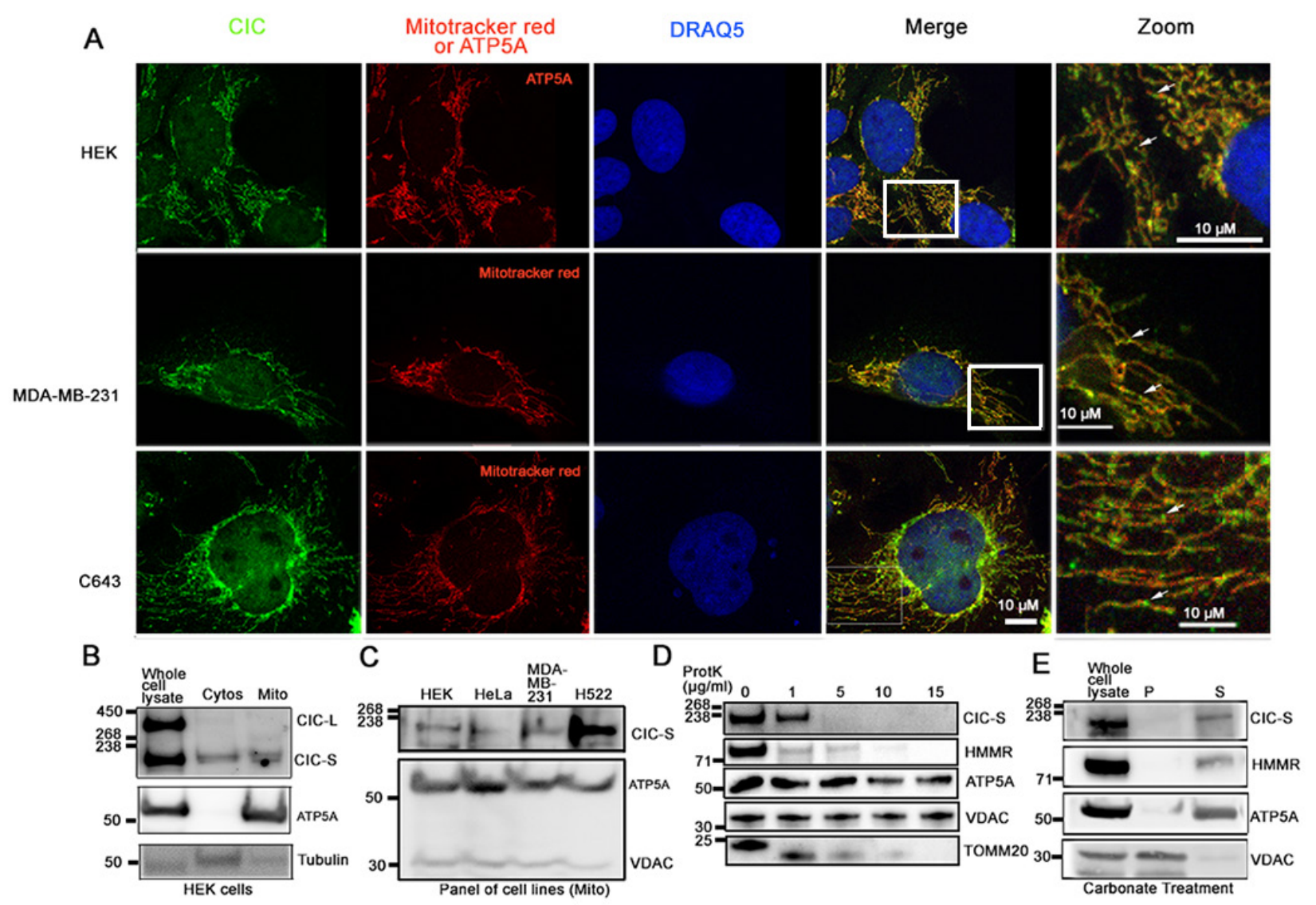

Figure 3: CIC-S is in close proximity to mitochondria and present in both cytosolic and mitochondrial fractions. A. To further study the subcellular localization of CIC, an immunofluorescence assay was performed using an anti-CIC antibody (green). Mitochondria were visualized using either Mitotracker red or an anti-ATP5A antibody (red). The nucleus was visualized using DRAQ5 stain (blue). HEK, MDA-MB-231 (breast carcinoma) and C643 (thyroid carcinoma) cells were observed using a confocal microscope. Boxes in the merge column indicate the zoomed area. Arrows in magnified images (labeled Zoom) show CIC-positive-puncta localizing along mitochondria. B. HEK cytosolic (Cytos) and mitochondrial (Mito) fractions were further isolated from cytoplasmic fractions and CIC-S was detected using western blots. To validate the fractionation method, control proteins tubulin (cytos) and ATP5A (mito) were also detected. CIC-S is enriched in the cytosolic and mitochondrial fractions. Mitochondrial fractions were isolated from human cancer cell lines HeLa (ovarian), MDA-MB-231 (breast) and H522 (lung) and CIC-S was detected using an anti-CIC antibody and western blots. Control proteins ATP5A and VDAC (mitochondrial) were detected. CIC-S was found in mitochondrial fractions in all cells. C. The mitochondrial fraction was isolated from HEK cells and a Proteinase K protection assay was performed using $0-15 \mu \mathrm{g} / \mathrm{ml}$ Proteinase K (ProtK). CIC-S protein was detected following treatment with Proteinase K. Control proteins VDAC (embedded in the mitochondrial outer membrane), ATP5A (mitochondrial matrix), TOMM20 (translocase of outer mitochondrial membrane), and HMMR (loosely associated with the outer mitochondria membrane) are also shown. ATP5A and VDAC but not CIC-S, TOMM20 and HMMR were protected at $15 \mu \mathrm{g} /$ $\mathrm{ml}$ ProtK indicating that CIC-S is localized outside mitochondria. Results shown are representative of three independent experiments. D. Mitochondrial fractions from HEK cells were treated with carbonate buffer and centrifuged to pellet $(\mathrm{P})$ proteins embedded in the mitochondrial membrane fraction. The supernatant $(\mathrm{S})$ contained proteins located in the inner membrane space, matrix and the proteins loosely bound to mitochondrial outer membrane. CIC-S was detected in the supernatant suggesting it is not embedded in the mitochondrial membrane. The result shown is representative of three experimental replicates. 
mutations in IDH and CIC-S might coordinately promote the production of $2 \mathrm{HG}$. To test this hypothesis, we derived stable HEK cell lines that ectopically expressed wild type CIC-S or mutant CIC-S (both R1515H and R201W) fused to N-terminal FLAG (hereafter referred to as F-CIC or F-CIC-R1515H or F-CIC-R201W), in combination with wild type IDH1 (hereafter referred to as IDH1-V5) or mutant IDH1-R132H (hereafter referred to as IDH1$\mathrm{R} 132 \mathrm{H}-\mathrm{V} 5$ ) fused to C-terminal V5 proteins (Figure 5A). We are aware of only two available $1 \mathrm{p} 19 \mathrm{q}$ co-deleted ODG cell lines, described above. Both lines grow very slowly and are resistant to transfection. Hence, we developed and used stably transformed HEK cells, as such cells were reported to exhibit properties similar to those of immature neurons [33]. To confirm previous reports [26, 29] in which cells expressing IDH1-R132H-V5 exhibited higher levels of $2 \mathrm{HG}$ compared to cell lines expressing wild type IDH1, we first quantified the levels of total 2HG (our assay measures both L-2-HG and D-2-HG) in our stable lines using MRM-MS. Our stable lines expressing IDH1R132H-V5 showed low-moderate levels of 2HG in early passages and stabilized after passage \#8, after which point they expressed approximately $>15$ fold $2 \mathrm{HG}$ compared to a stable line expressing IDH1-V5 (Supplementary Figure $\mathrm{S} 3 \mathrm{~A}$ ). Subsequent experiments detecting $2 \mathrm{HG}$ were thus performed with cells after passage \#8.

Next, we used MRM-MS to measure the levels of $2 \mathrm{HG}$ and $2 \mathrm{KG}$ in lines stably transfected with wild type and mutant expressing IDH and CIC constructs. Comparison of cells expressing mutant IDH1-R132H-V5 to cells expressing wild type IDH1 showed significant increases in $2 \mathrm{HG}(\mathrm{p}<0.0001$; Figure $5 \mathrm{~B})$. There were no significant differences in total $2 \mathrm{HG}$ levels between cells expressing wild type IDH1 alone or cells co-expressing wild type IDH1 with wild type F-CIC, F-CIC-R1515H, or F-CIC-R201W (Figure 5C). Cells expressing IDH1$\mathrm{R} 132 \mathrm{H}-\mathrm{V} 5$ alone and cells co-expressing IDH1R132H-V5/F-CIC, IDH1-R132H-V5/F-CIC-201W, or IDH1-R132H-V5/F-CIC-R1515H showed significant increases in 2HG levels ( $\mathrm{p}<0.0001$; $\mathrm{p}=0.0032$, $\mathrm{p}<0.0001$, respectively; Figure 5C). However, compared to cells coexpressing IDH1-R132H-V5/F-CIC, cells co-expressing IDH1-R132H-V5/F-CIC-R1515H further showed a significant increase in $2 \mathrm{HG}$ levels $(\mathrm{p}<0.0001$; Figure 5C). In the IDH1-R132H-V5 background, the most significant increase in $2 \mathrm{KG}$ levels were observed in cells co-expressing F-CIC-R201W ( $<<0.0001$; Figure 5C).

To assess whether our observations were specific to our HEK-derived lines, we derived stable HOG cell lines that ectopically expressed wild type CIC-S or mutant CIC-S (R1515H or R201W), in combination with wild type IDH1 or mutant IDH1-R132H. The HOG cell line was derived from a human glioma and expresses oligodendrocyte-specific proteins [34]. This cell line

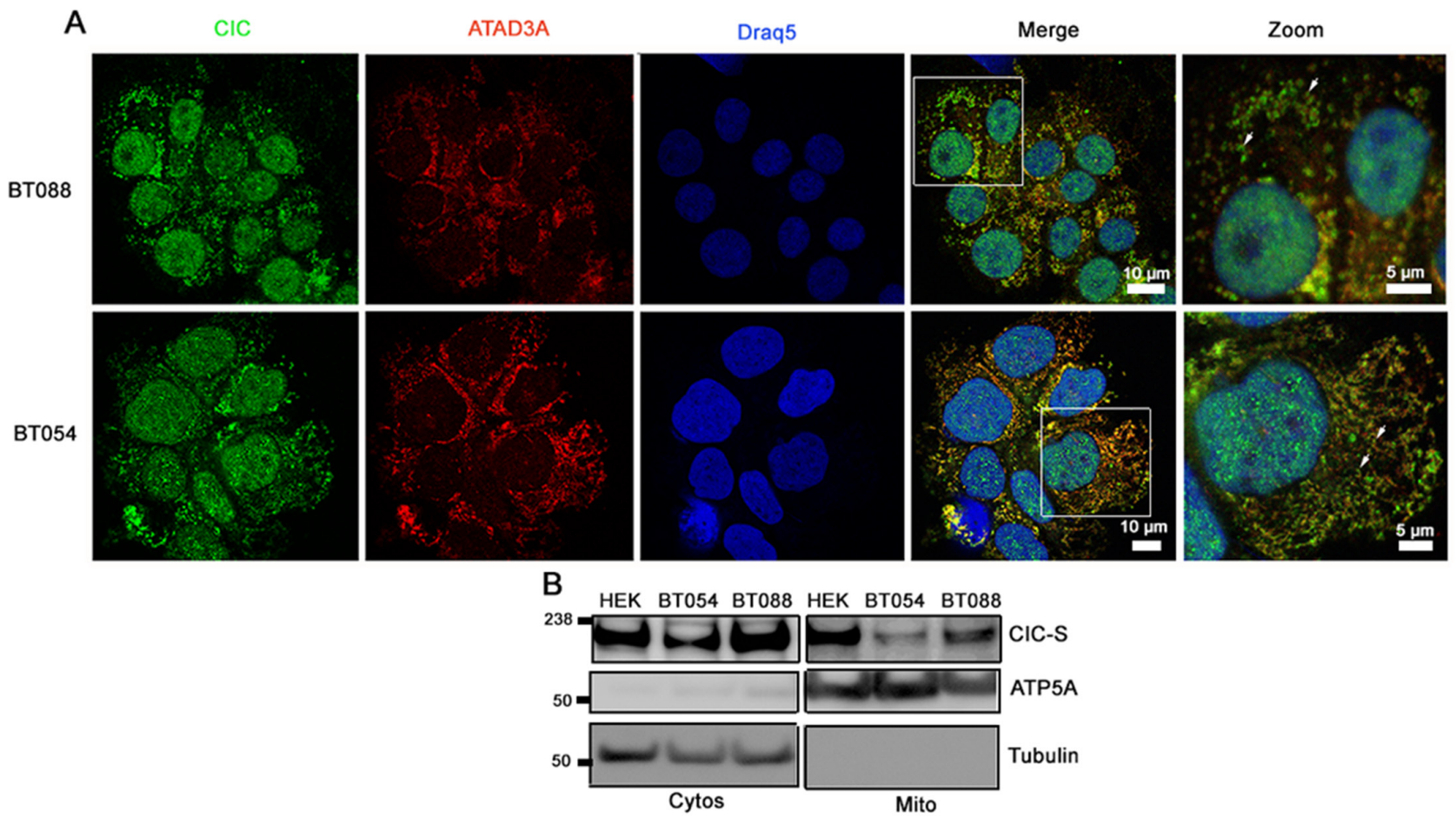

Figure 4: CIC-S localizes to mitochondria in 1p19q co-deleted oligodendroglioma cell lines. A. Subcellular localization of CIC in ODG cell lines BT088 and BT054 was detected using immunofluorescence. CIC was detected using an anti-CIC antibody and mitochondria were stained using an anti-ATAD3A antibody. Cells were visualized using confocal fluorescence microscopy. B. Cytosolic (Cytos) and mitochondrial (Mito) fractions of BT054 and BT088 were isolated and CIC-S was detected using western blots. Control proteins ATP5A (Mito) and Tubulin (Cytos) were also detected. 

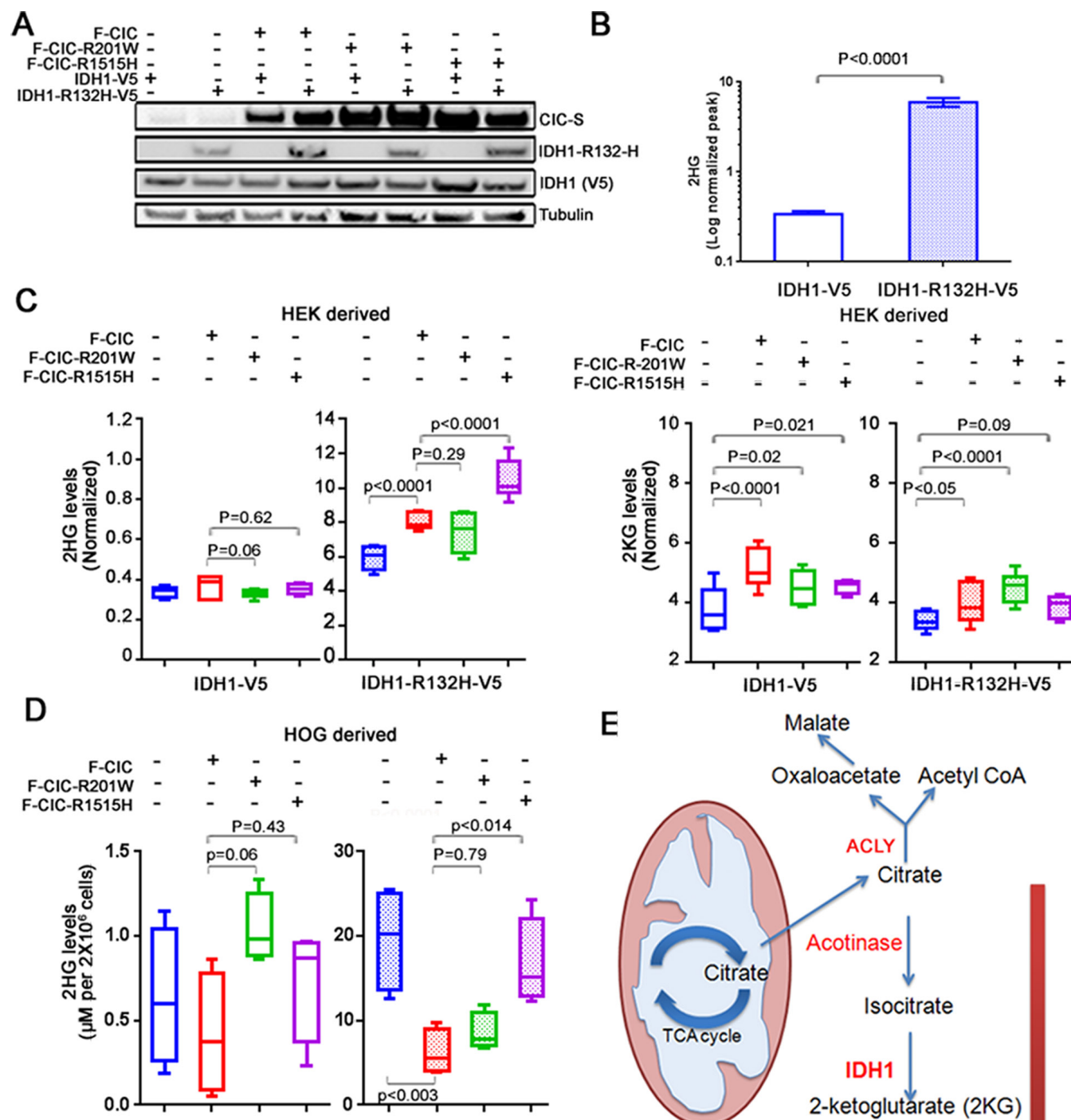

F-CIC-R1515H - $\quad-\quad+\quad-\quad-\quad+$

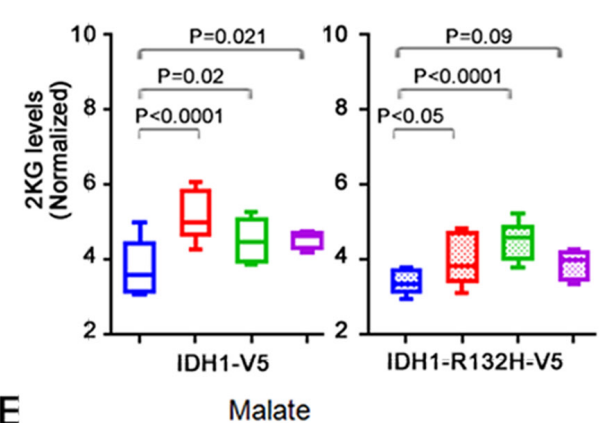

$\mathrm{E}$

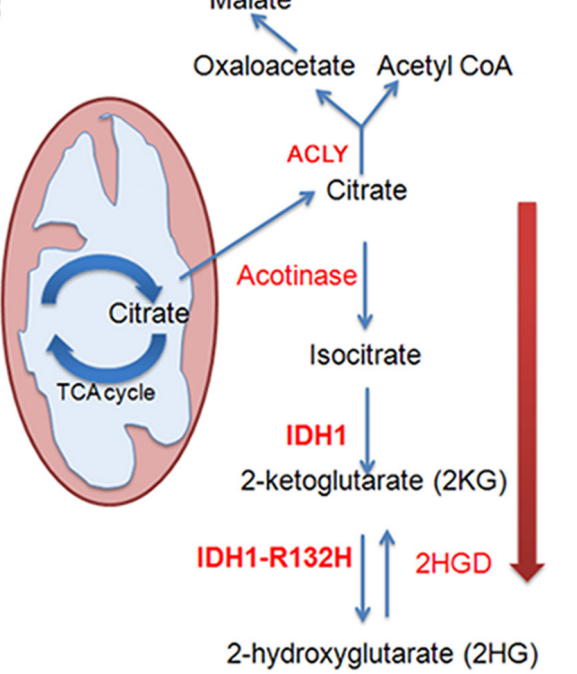

Figure 5: IDH1-R132H and mutant CIC coordinately regulate 2 HG production in vitro. A. Stable cell lines expressing either wild type IDH1-V5 or mutant IDH1-R132H-V5 in combination with wild type F-CIC or mutant F-CIC-R1515H or F-CIC-R201W were established and proteins detected using western blots. Expression of CIC and mutant IDH1-R132H were detected using antibodies specific to CIC or IDH1-R132H proteins. Mutant and wild type IDH1 proteins were fused to a V5 epitope and detected using an anti-V5 antibody. B. Levels of total cellular 2HG from HEK-derived stable cells (passage \#11-14) expressing wild type IDH1-V5 or IDH1-R132H-V5 were detected using targeted MRM-mass spectrometry. The values reported are averaged peak areas for $2 \mathrm{HG}$ that were normalized to the total area within each biological replicate. Error bars represent the SD from 3 independent biological replicates and 3 technical replicates of each (3 MS runs of the same sample), for a total of 9 data points for each experiment. C. Levels of $2 \mathrm{HG}$ or $2 \mathrm{KG}$ were detected using targeted MRM-mass spectrometry from HEK-derived cells co-expressing wild type or mutant CIC with wild type or mutant IDH1 (passage \#11-14). The values reported are averaged peak areas for $2 \mathrm{HG}$ or $2 \mathrm{KG}$ that were normalized to the total area within each biological replicate. Error bars represent the SD from 3 independent biological replicates and 3 technical replicates, for a total of 9 data points per experiment. Note the different scales of the Y-axes in the $2 \mathrm{HG}$ graphs. D. Levels of $2 \mathrm{HG}$ were detected using an enzymatic assay [37] from HOG-derived cells co-expressing wild type or mutant CIC with wild type or mutant IDH1 (passage \#10-13). 2HG levels $(\mu \mathrm{M}$ ) were calculated from standard curves established using D-2-Hydroxyglutaric acid. The averaged values reported were derived from four biological replicates. Note the different scales of the $\mathrm{Y}$ axes in the $2 \mathrm{HG}$ graphs. E. A model depicting the cooperative regulation of $2 \mathrm{HG}$ in cells co-expressing mutant IDH1-R132H and mutant CIC-R1515H/-201W. When high levels of citrate are produced in the mitochondria, citrate is shuttled to the cytosol. Cytosolic citrate may have two fates in cancer cells. (1) In actively proliferating cells, citrate is used by ACLY to produce Acetyl$\mathrm{CoA}$ in an ATP dependent manner. Acetyl-CoA is used for de novo lipid synthesis. (2) Citrate is used to produce 2-alpha ketoglutarate (2KG) by IDH1. Mutant IDH1_R132H converts 2KG into 2-alpha-hydroxyglutarate (2HG). CIC is in close proximity to mitochondria and appears to play a role in diverting citrate towards $2 \mathrm{HG}$ production. 
Table1: The candidate mitochondrial and metabolism related interaction partners of CIC. Columns 1 and 2 indicate UniProt protein name and accession number. Column 3 indicates the gene name, synonym and function. A total of six immunoprecipitation experiments (IP), 4 IP experiments with an endogenous antibody (E-1, E-2, E-3, W-1), and 3 experiments with a Myc (M-1) or GFP (G-1) or FLAG (F-1) antibody of N-terminus CIC fusion proteins (MYC-CIC, GFP-CIC and FLAGCIC, respectively) were conducted in HEK cells. Candidate proteins shown here were those observed in at least two independent IP experiments and not observed in the control IPs (4 IgG, and one each of FLAG, MYC or GFP empty vector) that were mitochondrial, or had metabolism related functions. Column 4 indicates the IP method for each candidate interaction partner. Column 5 indicates the Mascot score observed for each protein. Column 6 indicates the number of discrete (unique) peptides observed in the IP experiments.

\begin{tabular}{|c|c|c|c|c|c|}
\hline \multicolumn{2}{|c|}{ UniProt } & \multirow[b]{2}{*}{$\begin{array}{l}\text { Description; Gene name; Synonym } \\
\text { (Function) }\end{array}$} & \multicolumn{3}{|c|}{ Protein identification information } \\
\hline Name (Human) & Acession & & Type of IP & $\begin{array}{l}\text { Mascot } \\
\text { score }\end{array}$ & $\begin{array}{l}\text { Discrete } \\
\text { peptides }\end{array}$ \\
\hline \multicolumn{6}{|l|}{ metabolism: } \\
\hline \multirow[t]{3}{*}{ ACLY } & P53396 & ATP-citrate synthase; ACLY; & E-1 & 135 & 3 \\
\hline & & (ATP citrate-lyase) & E-2 & 388 & 9 \\
\hline & & & E-3 & 224 & 7 \\
\hline \multicolumn{6}{|l|}{ Mitochondrial } \\
\hline \multirow[t]{2}{*}{ ADT2 } & P05141 & $\begin{array}{l}\text { ADP/ATP translocase 2; SLC25A5; } \\
\text { ANT2 }\end{array}$ & E-2 & 104 & 2 \\
\hline & & $\begin{array}{l}\text { (exchange of cytoplasmic ADP with } \\
\text { mitochondrial ATP) }\end{array}$ & G-1 & 392 & 8 \\
\hline \multirow[t]{2}{*}{ ATD3A } & Q9NVI7 & $\begin{array}{l}\begin{array}{l}\text { ATPase family AAA domain- } \\
\text { containing protein 3A; ATAD3A }\end{array} \\
\end{array}$ & E-2 & 349 & 8 \\
\hline & & $\begin{array}{l}\text { (mitochondrial network organization, } \\
\text { mitochondrial DNA replication) }\end{array}$ & E-3 & 197 & 5 \\
\hline \multirow[t]{2}{*}{ ATPA } & P25705 & $\begin{array}{l}\text { ATP synthase subunit alpha, } \\
\text { mitochondrial: ATP5A1; ATP5A }\end{array}$ & M-1 & 104 & 3 \\
\hline & & $\begin{array}{l}\text { (alpha subunit of F1-ATPase catalytic } \\
\text { core) }\end{array}$ & G-1 & 96 & 3 \\
\hline \multirow[t]{2}{*}{ ATPB } & P06576 & $\begin{array}{|lc|}\text { ATP synthase subunit beta, } \\
\text { mitochondrial; ATP5B; }\end{array}$ & E-2 & 105 & 2 \\
\hline & & $\begin{array}{l}\text { (beta subunit of F1-ATPase catalytic } \\
\text { core) }\end{array}$ & G-1 & 87 & 2 \\
\hline \multirow[t]{4}{*}{ DHX30 } & Q7L2E3 & $\begin{array}{l}\text { Putative ATP-dependent RNA helicase } \\
\text { DHX30; DHX30; DDX30 }\end{array}$ & E-1 & 142 & 5 \\
\hline & & (Associates with mitochondrial DNA) & E-2 & 64 & 2 \\
\hline & & & E-3 & 93 & 3 \\
\hline & & & M-1 & 584 & 12 \\
\hline \multirow[t]{3}{*}{ DNM1L } & O00429 & $\begin{array}{l}\text { Dynamin-1-like protein; DNM1L; } \\
\text { DLP1 }\end{array}$ & E-1 & 380 & 8 \\
\hline & & $\begin{array}{lll}\begin{array}{l}\text { (mitochondrial } \\
\text { division) }\end{array} & \text { and } & \text { peroxisomal } \\
\end{array}$ & E-2 & 110 & 3 \\
\hline & & & W-1 & 374 & 10 \\
\hline \multirow[t]{2}{*}{ EFTU } & P49411 & $\begin{array}{l}\text { Elongation factor Tu, mitochondrial; } \\
\text { TUFM; }\end{array}$ & E-2 & 184 & 3 \\
\hline & & (mitochondrial protein sysnthesis) & G-1 & 206 & 4 \\
\hline \multirow[t]{2}{*}{ GRP75 } & P38646 & $\begin{array}{l}\text { Stress-70 protein, mitochondrial; } \\
\text { HSPA9; }\end{array}$ & F-1 & 1214 & 22 \\
\hline & & (chaperone) & G-1 & 430 & 8 \\
\hline \multirow[t]{3}{*}{ HMMR } & O75330 & $\begin{array}{lcc}\begin{array}{l}\text { Hyaluronan } \\
\text { receptor; HMMR; RHAMM }\end{array} & \text { motility } \\
\end{array}$ & E-1 & 38 & 1 \\
\hline & & (cell motility) & E-2 & 904 & 20 \\
\hline & & & $\mathrm{W}-1$ & 151 & 4 \\
\hline
\end{tabular}




\begin{tabular}{|l|l|l|l|l|l|}
\hline MMAB & Q96EY8 & $\begin{array}{l}\text { Cob(I)yrinic acid a,c-diamide } \\
\text { adenosyltransferase, mitochondrial; } \\
\text { MMAB; }\end{array}$ & E-2 & 470 & 7 \\
\hline & & $\begin{array}{l}\text { (adenosylcobalamin biosynthesis) } \\
\text { PTCD3 }\end{array}$ & E-3 & 200 & 5 \\
\hline & $\begin{array}{l}\text { Pentatricopeptide repeat-containing } \\
\text { protein 3, mitochondrial; PTCD3; } \\
\text { MRPS39 }\end{array}$ & E-1 & 291 & 6 \\
\hline & (Mitochondrial RNA-binding protein) & E-2 & 64 & 1 \\
\hline Other & & & M-1 & 41 & 1 \\
\hline ATX2L & Q8WWM7 & $\begin{array}{l}\text { Membrane; Peripheral membrane } \\
\text { protein }\end{array}$ & E-1 & 754.9 & 17 \\
\hline & & & E-2 & 1316 & 26 \\
\hline & & & E-3 & 1223.5 & 26 \\
\hline
\end{tabular}

was previously determined not to harbour $1 \mathrm{p} 19 \mathrm{q}$ codeletions or mutations in the $I D H 1$ or $I D H 2$ genes [35, $36]$. We determined $2 \mathrm{HG}$ levels in our stably transfected HOG cell lines using an enzymatic assay that is based on the detection of stoichiometrically generated NADH that was generated during the conversion of $2 \mathrm{HG}$ to $2 \mathrm{KG}$ in the presence of the enzyme (D)-2-hydroxyglutarate dehydrogenase (HGDH) and nicotinamide adenine dinucleotide $\left(\mathrm{NAD}^{+}\right)$[37]. In agreement with our HEK stable cell lines, comparison of cells co-expressing IDH1R132H-V5 and F-CIC to cells co-expressing IDH1R132H-V5 and F-CIC-R1515H showed a striking increase in $2 \mathrm{HG}$ levels $(\mathrm{p}<0.014$; Figure $5 \mathrm{D})$. Similar to our HEK cells, comparison of cells co-expressing IDH1-R132H-V5 and F-CIC to cells co-expressing IDH1-R132H-V5 and F-CIC-R201W did not show an increase in 2HG levels $(\mathrm{p}=0.79$; Figure $5 \mathrm{D})$. In contrast to the HEK-derived stable line, the HOG stable line expressing IDH1R132H-V5 alone produced high levels of 2HG. However, co-expression of wild type F-CIC in combination with mutant IDH1-R132H significantly reduced the 2HG levels $(\mathrm{p}<0.003)$, indicating that $\mathrm{CIC}$ expression can modulate $2 \mathrm{HG}$ production. Taken together, our results indicate that expression of mutant CIC-R1515H, but not wild type CIC or CIC-R201W, can cooperate with mutant IDH1-R132H to increase cellular levels of 2HG (Figure 5E).

Examining the expression levels of F-CIC, F-CIC$\mathrm{R} 1515 \mathrm{H}$, and F-CIC-R201W over passages (passage \#2-15) in HEK-derived stable cells lines showed gradually decreasing levels of F-CIC, but both mutant F-CIC-R1515H and F-CIC-R201W proteins were stable (Supplementary Figure S3B). Although all the HEKderived stable cell lines expressed similar levels of IDH1$\mathrm{R} 132 \mathrm{H}$ in early passages (passage \#2-4), the stable line expressing mutant F-CIC-R1515H showed the highest level of IDH1-R132H-V5 protein in late passages (Supplementary Figure S3C). Similarly, the HOG-derived stable cell line expressing mutant F-CIC-R1515H showed the highest level of IDH1-R132H-V5 protein in later passages (Supplementary Figure S3D), which may explain the significant increase in $2 \mathrm{HG}$ levels in these lines.

\section{CIC interacts with metabolism and mitochondrial related proteins}

To further shed insight into CIC function, we sought to identify CIC interacting proteins in the cytoplasm. We performed three co-immunoprecipitations (Co-IP) of cytoplasmic fractions using an anti-CIC antibody and rabbit IgG IPs as controls. We also transiently expressed CIC-S proteins with N-terminal FLAG, Myc or GFP tags in HEK cells, extracted the cytoplasmic fractions and performed IPs using anti-FLAG, anti-Myc or anti-GFP antibodies. Cells transfected with empty FLAG, Myc or GFP vectors served as controls. Isolated protein complexes were characterized using liquid chromatography and tandem mass spectrometry (LC-MS/MS). Consistent with a previous report showing interaction of CIC with Ataxin family members [10], we detected Ataxin2L in our IP experiments (Table 1). We also identified ACLY, a metabolism-related protein and 11 mitochondrial proteins as high-confidence candidate interaction partners of CIC in our LC-MS/MS experiments (Table 1).

Since ACLY is involved in cytosolic citrate metabolism and alterations in citrate metabolism are important in malignancies [24], we chose to further study the ACLY/CIC interaction. Because the ACLY/CIC interaction was observed in endogenous IP experiments (Table 1, Figure 6A), we confirmed the interaction using a reciprocal IP strategy. We used an anti-ACLY antibody and western blots to detect CIC-S in the IP derived from a HEK cytoplasmic fraction (Figure 6A). We also co-expressed F-CIC and ACLY fused to a C-terminal V5 epitope (ACLY-V5) in HEK293 cells. CIC immunoprecipitation using anti-FLAG antibody also captured ACLY; however, IP with anti-FLAG in the absence of F-CIC failed to immunoprecipitate ACLY (Figure 6B), compatible with the notion that CIC-S forms complexes with ACLY. 


\section{Mutations in CIC lead to reduced pACLY}

Phosphorylation of ACLY, including at Serine 454 (hereafter referred to as pACLY), contributes to increased ACLY stability and activity [38-40]. ACLY converts cytosolic citrate to acetyl $\mathrm{CoA}$, which promotes cancer cell proliferation [40, 41]. IDH1 converts cytosolic isocitrate, derived from citrate, into alpha-ketoglutarate (2KG). Mutant IDH1-R132H further diverts this pathway towards the production of the oncometabolite $2 \mathrm{HG}$ (Figure 5D). These two pathways may thus compete for citrate. Having observed that CIC interacts with ACLY (Table 1,
Figure 6A), we sought to determine the levels of ACLY or pACLY in cells expressing wild type or mutant CIC. The HEK-derived stable cell lines grown in DMEM $+10 \%$ FBS did not show differences in growth or morphology. In contrast, when grown in serum free media with growth factors (ODG culturing media; see Methods), cells expressing mutant $\mathrm{CIC}$ formed reduced numbers of clones compared to cells expressing wild type CIC (Figure 6B). We measured the levels of total ACLY and pACLY after exposing our HEK stable cell lines to serum free media with or without growth factors for $6 \mathrm{hrs}$. Compared to cells expressing wild type CIC, we saw pACLY reductions in cells expressing either of the mutant CIC protein
A.

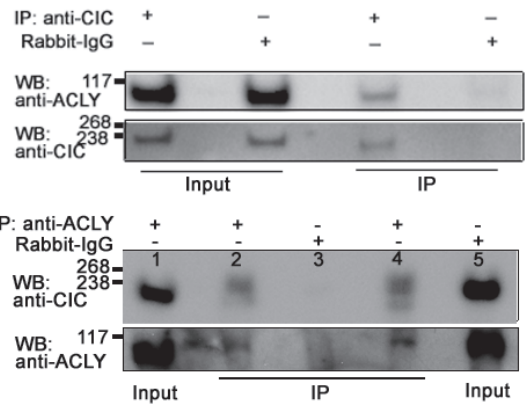

B.

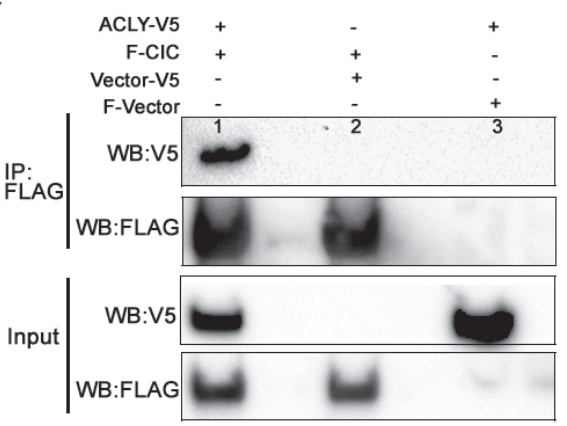

C.

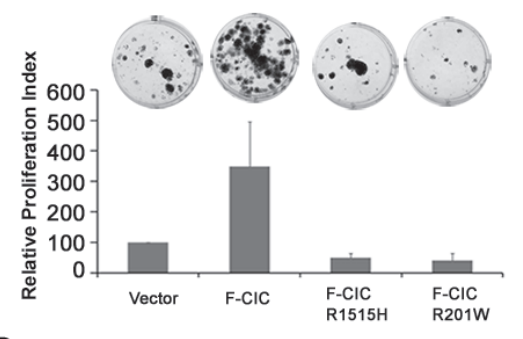

D.
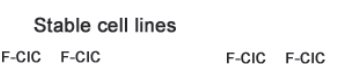

E. Transient transfection F-CIC F-CIC $\begin{array}{ccc}\text { F-CIC F-CIC } & \text { F-CIC F-CIC } \\ \text { vector F-CIC R1515H R201W vector F-CIC R1515H R201W }\end{array}$
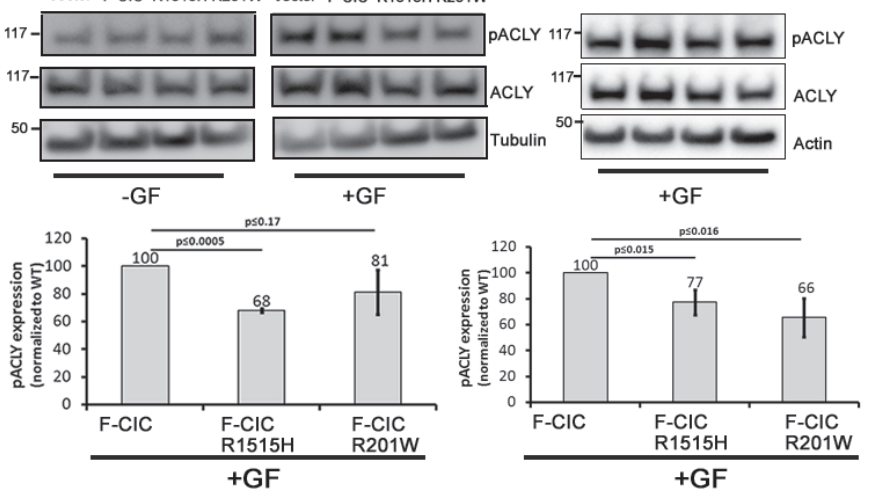

Figure 6: pACLY levels were low in cells expressing mutant CIC proteins. A. Immunoprecipitations with an anti-CIC antibody or rabbit IgG using cytosolic (nucleus-free and mitochondria-free) HEK cell fractions were performed and ACLY was detected using an anti-ACLY antibody. A reciprocal immunoprecipitation using an anti-ACLY antibody or rabbit-IgG and the cytosolic fraction of HEK cells was also performed and CIC-S was detected using an anti-CIC antibody and western blot analyses. Lanes 1 and 5 are input lysates for IP with ACLY antibody and IgG respectively. Two aliquots of IP with anti-ACLY were loaded onto Lanes 2 and 4. A control IP with IgG is shown in lane 3. The figures are representative of three experimental replicates. B. FLAG-tagged CIC (bait protein) and V5 tagged ACLY (prey) were co-expressed in HEK293 cells. Co-immunoprecipitation was carried out using anti-FLAG antibody. CIC and ACLY were detected using anti-FLAG and anti-V5 antibodies respectively and western blot analysis. ACLY was detected only in the presence of FLAG-CIC (lane1) and although it was expressed, not detected in the absence of the FLAG-CIC (lane 3), thus confirming that CIC interacts with ACLY in these cells. C. Stable cell lines expressing vector, F-CIC, F-CIC-R1515H or F-CIC-R201 W were exposed to serum free media containing growth factors. Proliferating cell colonies were observed two weeks after culturing using crystal violet stain. To generate proliferation indices, crystal violet stain retained in the clones was re-suspended in $10 \%$ acetic acid and measured at $\mathrm{A}_{590}$. Proliferation indices were calculated relative to cells expressing vector only (endogenous CIC). Standard deviation (SD) values shown are from 3 independent experiments. D. Stable cell lines expressing F-CIC or F-CIC-R1515H or F-CIC-R201W were exposed to serum free media with or without growth factors (+GF or -GF respectively) for 6 hrs. Levels of total ACLY and phosphorylated ACLY (pACLY) were determined using western blot analysis. Densitometry quantitations of pACLY/tubulin for stable cell lines expressing F-CIC or F-CIC-R1515H or F-CIC-R201W with growth factors relative to F-CIC expression are shown. SDs were calculated from three independent experiments. P-values shown were calculated using Student's t-test. E. HEK293 cells were transiently transfected with vector, F-CIC, F-CIC-R1515H or F-CIC-R201W. Cells were exposed to serum free media with growth factors (+GF) for $48 \mathrm{hrs}$ after transfections. Levels of total ACLY and pACLY were determined using western blot analysis. Densitometry quantitations of pACLY/tubulin for stable cell lines expressing F-CIC or F-CIC$\mathrm{R} 1515 \mathrm{H}$ or F-CIC-R201W relative to F-CIC expression are shown. SDs were calculated from three independent experiments. P-values shown were calculated using Student's t-test. 
constructs but the most extreme reduction of pACLY was observed in cells ectopically expressing F-CIC-R1515H $(p<0.0005)$ (Figure 6C). To confirm this observation, we transiently transfected wild type and mutant CIC proteins and measured the levels of ACLY and pACLY. Similar to the stable cell lines, cells transiently transfected with both F-CIC-R1515H and F-CIC-R201W showed reductions in
pACLY ( $<<0.015$ and $\mathrm{p}<0.016$ respectively) compared to the wild type CIC (Figure 6E) supporting the notion that CIC mutations affect pACLY levels.

We next investigated whether IDH1 and CIC mutations could affect ACLY or pACLY levels. We used our HEK and HOG-derived stable cell lines expressing mutant CIC in wild type or mutant IDH1 backgrounds.

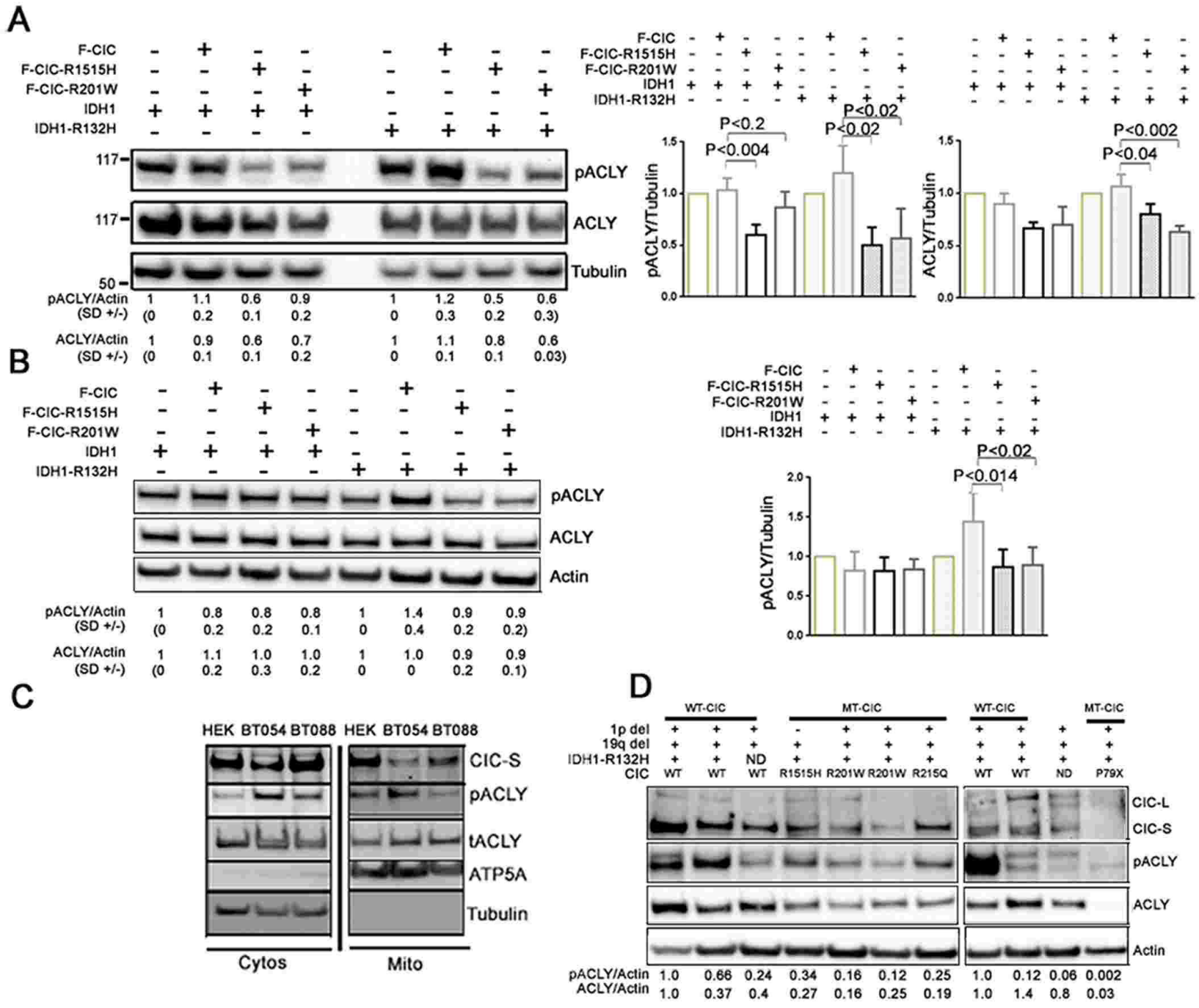

Figure 7: Cells expressing mutantCIC proteins exhibit reductions in pACLY. A. Western blot analyses were used to detect total ACLY and pACLY in HEK-derived cells grown for $48 \mathrm{hrs}$ in serum free culturing conditions with $0.5 \%$ FBS and growth factors. Densitometry quantitations of pACLY/tubulin and ACLY/tubulin levels with standard deviations (SD) are shown below the western blots. Relative protein levels of pACLY and ACLY in cells expressing mutant CIC proteins (F-CIC-R1515H, or F-CIC-R201W) were derived relative to control cells expressing vector only. As shown in the bar graph, independent of IDH mutational status, CIC-R1515H mutation resulted in significant reduction in pACLY $(\mathrm{p}<0.01)$. The $\mathrm{p}$-value was calculated from three independent experiments using one-way ANOVA analysis. B. Total ACLY and pACLY were also detected in independent HOG-derived stable cell lines grown for $72 \mathrm{hrs}$ in serum free culturing conditions with $0.5 \%$ FBS and growth factors. Similar to HEK-derived stable cells, independent of IDH mutational status, the highest level of reduction in pACLY was observed in cells expressing mutant CIC (-R1515H). C. Cytosolic and mitochondrial fractions were isolated from ODG cells BT054 (IDH1 ${ }^{+/ R 132 \mathrm{H}} ; \mathrm{CIC}^{+/}$) and BT088 (IDH1 ${ }^{+}$; $\mathrm{CIC}^{\mathrm{R} 1515 \mathrm{H} /}$ ) and total ACLY and pACLY were detected in both cytosolic (Cytos) and Mitochondrial (Mito) fractions. The images shown are representative of 3 independent experiments. D. The levels of ACLY and pACLY in 1p19q co-deleted ODG tumours with known CIC and IDH1 status ( $\mathrm{n}=10)$ were determined using western blot analysis. Densitometry quantitations of pACLY/tubulin and ACLY/tubulin levels were determined and are shown below the western blots. Tumours with wild type CIC $(n=5)$ showed elevated levels of either ACLY or pACLY compared to the tumours with mutant CIC proteins $(\mathrm{n}=5)$. The most striking reduction in ACLY and pACLY was observed in a tumour sample with a truncated CIC protein (P79X). 
In HEK stable lines, we saw significant differences in the levels of pACLY in cells expressing F-CIC-R1515H compared to F-CIC on both IDH1-V5 $(\mathrm{p}<0.004)$ and IDH1-R132H-V5 $(\mathrm{p}<0.02)$ backgrounds (Figure 7A). Cells expressing F-CIC-R201W compared to F-CIC also showed significant differences in the levels of pACLY on IDH1-R132H-V5 backgrounds ( $<<0.02$; Figure 7A). We saw significant differences in the levels of total ACLY in cells expressing either F-CIC-R1515H or F-CIC-R201W compared to F-CIC in IDH1-R132H-V5 backgrounds $(p<0.02$ and $p<0.001$ respectively; Figure $7 \mathrm{~A})$. In HOG stable lines, we also saw reduced levels of pACLY in cells co-expressing mutant IDH1-R132H-V5 and mutant F-CIC-R1515H or F-CIC-R201W compared to wild type F-CIC $(p<0.014$ and $p<0.02$ respectively; Figure $7 B)$.

We next assessed pACLY levels in ODG cell lines with wild type CIC (BT054; IDH1 $1^{+/ 2132 H} / \mathrm{CIC}^{+/-}$) and mutant CIC-R1515H (BT088; IDH1 ${ }^{+/+} / \mathrm{CIC}^{\mathrm{R} 1515 \mathrm{H} /-}$ ). In agreement with the results we obtained using our stably transfected cell lines, reduced pACLY levels were observed in BT088 cells compared to BT054 cells, both in the cytoplasmic and mitochondrial fractions (Figure 7C). We next measured ACLY and pACLY levels in 1p19q co-deleted oligodendroglioma patient samples with known CIC and IDH1 status. In agreement with our in vitro findings, tumours with wild type $\mathrm{CIC}(\mathrm{n}=5)$ showed elevated levels of either ACLY or pACLY compared to tumours with mutant CIC proteins ( $\mathrm{n}=5$; Figure 7D). Strikingly, a tumour sample with a truncated CIC protein (P79X) showed dramatic reductions in ACLY and pACLY. We interpret these findings to indicate that wild type CIC forms protein complexes with ACLY, and CIC mutants act to reduce the levels of pACLY and/or ACLY. As depicted in Figure 5C and D, reduction in ACLY/pACLY levels in our cells and in 1p19q co-deleted tumours expressing mutant CIC is consistent with the notion that mutations in CIC facilitate the diversion of citrate towards the production of $2 \mathrm{HG}$.

\section{Mutations in CIC and IDH1 cooperate to reduce proliferation and clonogenicity}

Since pACLY levels were reduced and $2 \mathrm{HG}$ levels were increased in cells expressing CIC-R1515H and IDH1$\mathrm{R} 132 \mathrm{H}$, we predicted that mutant CIC, in cooperation with mutant IDH1, may alter cell proliferation, survival or death. To compare the proliferation of cells carrying F-CIC-R1515H or F-CIC-R201W and IDH1-R132H-V5 to cells expressing wild type F-CIC with IDH1-V5, we performed clonogenic assays combined with crystal violet proliferative assays (hereafter referred to as crystal violet assays) under serum free conditions supplemented with $0.5 \%$ Fetal Bovine serum (FBS) and growth factors. Without $0.5 \%$ FBS, both HEK and HOG cells do not adhere and form spheres; however, with $0.5 \%$ FBS, HEK and HOG cells can adhere and proliferate. In HEK stable cells, ectopic co-expression of F-CIC with IDH1-V5 showed a $33 \%$ relative increase in proliferation compared to cells ectopically expressing IDH1-V5 alone $(\mathrm{p}<0.005$; Figure 8A). Expression of IDH1-R132H-V5 alone decreased the relative proliferation of cells $(44 \%+/-12$; $\mathrm{p}<0.001)$ compared to IDH1-V5. Ectopic co-expression of F-CIC with IDH1-R132H-V5 partially rescued this low proliferative phenotype (Figure 8A). These findings suggest that $\mathrm{CIC}$ and IDH1 can cooperate to influence cell proliferation in vitro. Cells expressing mutant CIC proteins $\mathrm{R} 1515 \mathrm{H}$ or $\mathrm{R} 201 \mathrm{~W}$ in a wild type IDH1 background showed significant decreases in relative cell proliferation compared to F-CIC with IDH1-V5 co-expression (reduced by $97 \%$ and $119 \%$ respectively; $\mathrm{p}<0.0001$ for both). Compared to cells expressing IDH1-R132H-V5 or F-CIC-1515H alone, cells co-expressing IDH1-R132H$\mathrm{V} 5 / \mathrm{F}-\mathrm{CIC}-1515 \mathrm{H}$ showed further reductions $(36 \%$ and $28 \%$ respectively) in relative cell proliferation (Figure 8A). Similarly, in HOG-derived stable lines, expression of IDH1-R132H-V5 alone decreased the relative proliferation of cells $(43+/-7 \% ; \mathrm{p}<0.001)$ compared to IDH1-V5; ectopic co-expression of F-CIC with IDH1-R132H-V5 partially rescued the low proliferative phenotype (Figure 8A). Compared to cells expressing IDH1-R132H-V5, cells co-expressing IDH1-R132H-V5 and F-CIC-1515H or IDH1-R132H-V5 and F-CIC-201W showed further reductions (13 and 14\% respectively) in relative cell proliferation (Figure 8A). Similar observations were also found in media without FBS in both HEK293 and HOGderived stable cell lines (Figure 8B). Cells co-expressing wild type CIC and mutant IDH1 formed numerous spheres that were also larger in size compared to cells expressing mutant IDH1 and either mutant CIC (-R1515H/-R201W) proteins (Figure 8B). These findings are in agreement with the notion that mutations in IDH1 and CIC are cooperatively regulating cell clonogenicity. Although cells expressing IDH1-R132H-V5 and F-CIC-R1515H or IDH1-R132H-V5 and F-CIC-R201W exhibited dead cells after one week, we did observe survival of a small fraction of cells that continued to thrive.

In stable HEK cells expressing mutant F-CIC$\mathrm{R} 1515 \mathrm{H}$, we observed cells displaying anoikis after 48 hours in culture. To assess whether these cells were undergoing caspase dependent cell death, we measured the activity of caspases $3 / 7$ and the levels of cleaved PARP (product of caspases 3 and 7 activity) in our CIC wild type/mutant HEK-derived stable lines in combination with IDH1-R132H-V5. Cells expressing F-CIC-R1515H in either the IDH1-V5 or IDH1-R132H-V5 background showed significant increases (Figure 8C; $<<0.0001$ ) in caspase activity and yielded higher levels of cleaved PARP compared to vector only, wild type CIC and CICR201W (Figure 8D). Reduction in ACLY and pACLY elicited cell death in non-small cell lung cancer cells [42] and pancreatic beta cells [43], and so we sought 

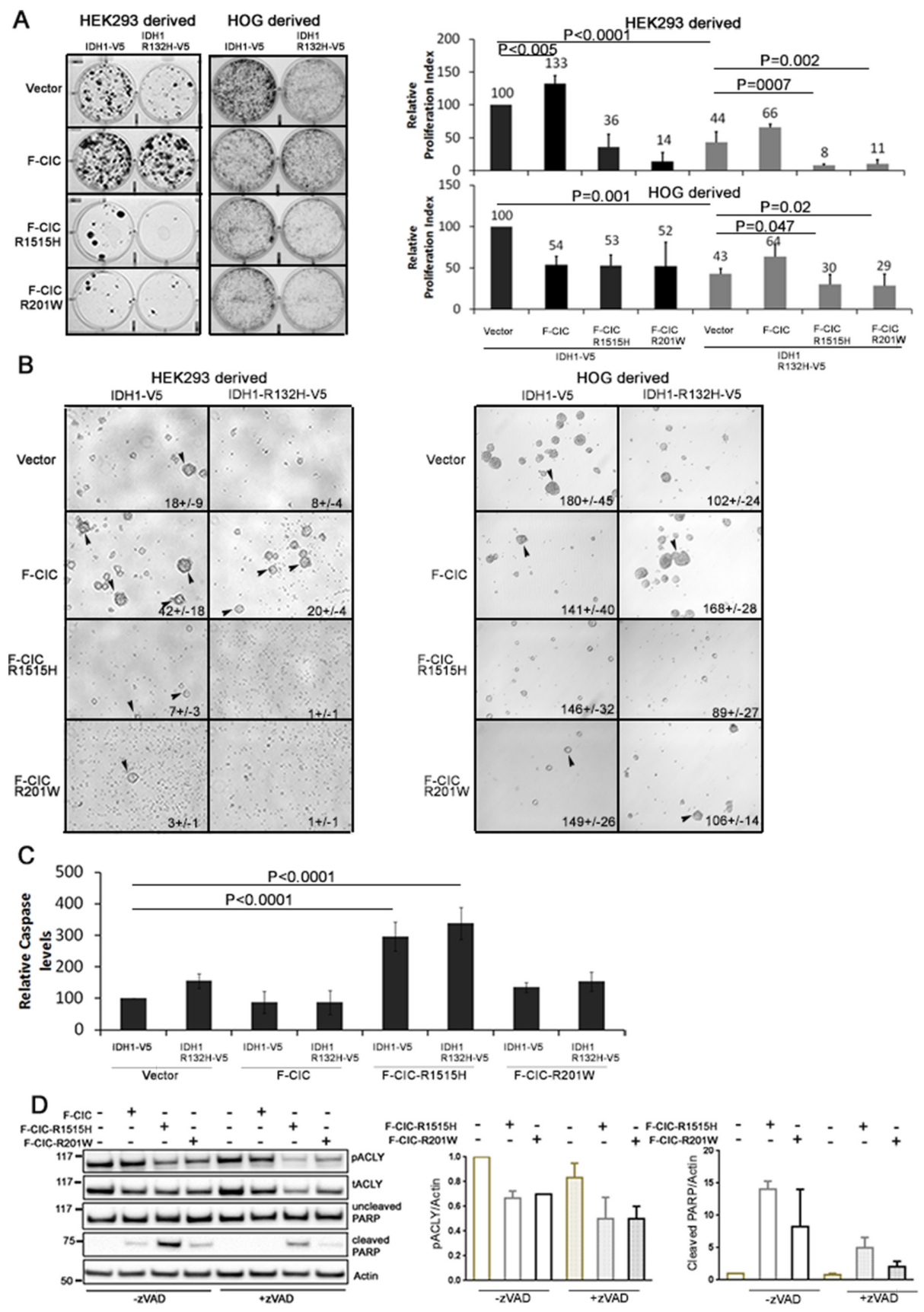

Figure 8: CIC and IDH1 coordinately regulate cell clonogenicity and mutations in CIC regulate cell death by reducing pACLY levels in vitro. A. Clonogenic assays of HOG and HEK-derived stable cell lines were performed in serum free media with low FBS and growth factors. Proliferating cell colonies were visualized using crystal violet stain one week (HOG) or two weeks (HEK) after culturing. Proliferation indices were calculated relative to cells expressing IDH1-V5 and vector only (endogenous CIC). Error bars represent the SD from 3 independent experiments. Multiple comparisons using mean values were performed using one-way ANOVA. B. Stable cell lines were cultured under oligodendroglioma cell growing conditions without FBS to form spheres. Spheres were viewed under an inverted light microscope. Images were taken 1 week after plating. Compared to cells expressing wild type IDH1 only or wild type IDH1 and CIC, sphere formation was reduced in cells expressing mutant CIC and mutant IDH1. Sphere counts (+/- standard deviation) represent results obtained from 3 independent experiments. C. Stable cell lines were grown in serum free media with $0.5 \% \mathrm{FBS}$ and growth factors for $72 \mathrm{hrs}$ and caspase 3 and 7 expression was determined using the Caspase-Glo ${ }^{\circledR}$ 3/7 assay. Caspase levels were calculated relative to cells expressing IDH1-V5 and vector only (endogenous CIC). Cells expressing F-CIC-1515H showed the highest levels of caspase activity $(\mathrm{p}<0.0001)$. Error bars represent the SD from 3 independent experiments. D. Stable lines expressing mutant IDH1-R132H-V5 combined

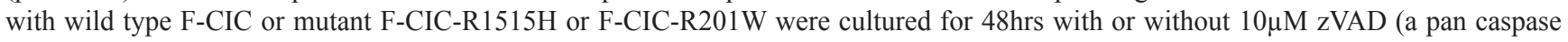
inhibitor) to determine whether reduction in pACLY led to cell death. Levels of total ACLY, pACLY and cleaved PARP were detected using western blots. zVAD treatment significantly reduced cleaved PARP in cells expressing mutant CIC. Western blots are representative of 3 biological replicates and the bar graphs shown are densitometry quantitations from 3 biological replicates. 
to confirm this in our model system. To inhibit caspase activity, we treated cells with a pan caspase inhibitor Z-VAD-FMK (zVAD). After 48 hours in culture, cells displaying anoikis were not observed in zVAD treated cells. Western blot analysis showed dramatic reduction of cleaved PARP in F-CIC-R1515H zVAD treated cells (Figure 8D) compared to untreated cells and showed that pACLY levels were lower in these cells. These findings are compatible with the notion that reductions in pACLY led to anoikis and cell death. Increased caspase activity and reduced clonogenicity in cell lines expressing mutant IDH and the $\mathrm{R} 1515 \mathrm{H}$ mutant $\mathrm{CIC}$ in vitro appears to mimic the slow growing nature of ODGs and may explain why it is difficult to grow ODGs with IDH1 and CIC mutations in vitro $[30,44,45]$. It is noteworthy that to date, no $1 \mathrm{p} 19 \mathrm{q}$ co-deleted ODG cell lines with both IDH1 and CIC point mutations are available, despite $70 \%$ of ODGs carrying mutations in both genes.

\section{DISCUSSION}

Although CIC has been implicated in human diseases including cancers, the biology of CIC in mammalian cells remains poorly understood. Using immunoblotting and MRM mass spectrometry assays, we have confirmed the presence of two forms of endogenous CIC in HEK, oligodendroglioma (ODG) cells and tumour tissues (Figure 1, Figure 7). We further determined the subcellular localization of CIC-S (cytoplasm) and CIC-L (nucleus) in human cells. Localization of these isoforms to different compartments may indicate that these isoforms have distinct functions.

CIC was reported to be a transcriptional repressor in Drosophila nucleii and in mammalian cells [16, 17]. As far as we are aware, ours is the first study to report the localization of endogenous CIC-S and its proximity to mitochondria, the first study to report CIC-protein interactions and the first study to link CIC and mutations therein to roles in citrate metabolism. Cytosolic citrate is converted into $2 \mathrm{KG}$ by IDH1 and IDH1-R132H mediates the conversion of $2 \mathrm{KG}$ into $2 \mathrm{HG}$, which accumulates at high levels in cells. ACLY on the other hand, converts cytosolic citrate into Acetyl-CoA that is essential for de novo lipid synthesis. In this paper, we established a possible mechanism of cooperative regulation of cytosolic citrate by mutant IDH1 and CIC.

Since IDH1 is the most frequently mutated gene in $1 \mathrm{p} 19 \mathrm{q}$ co-deleted ODG and CIC is mutated in $\sim 70 \%$ of oligodendrogliomas, we studied the effects of expressing wild type and mutant CIC in combination with IDH1$\mathrm{R} 132 \mathrm{H}$ on cell proliferation, cell survival and cell death using ODG cell culturing conditions. We for the first time showed a cooperative regulation of $2 \mathrm{HG}$ in mammalian cells expressing both mutant IDH1-R132H-V5 and the R1515H mutant CIC. Since high levels of $2 \mathrm{HG}$ can be toxic to cells [26], the cooperative increase in $2 \mathrm{HG}$ in the mutant cells expressing both IDH1-R132H-V5 and F-CIC$\mathrm{R} 1515 \mathrm{H}$ may explain at least in part the cooperative reduction in clonogenicity in these stable cell lines under ODG culturing conditions. Among the somatic mutations observed in CIC in gliomas, $41 \%$ and $7 \%$ of all missense mutations were observed in the HMG binding domain and protein binding domain, respectively $[2,5,7,8]$. Since HEK293 cells co-expressing IDH1-R132H-V5 with F-CIC or F-CIC-R201W produce less $2 \mathrm{HG}$ compared to the cells co-expressing IDH1-R132H-V5 and F-CIC-R1515H, it is tempting to speculate that in gliomas, missense mutations in the HMG domain alter its function to produce a $2 \mathrm{HG}$ level for tumour cells that balances cell survival and increased tumorogenicity, and for this reason such mutations are observed more frequently than missense mutations in the protein binding domains. In contrast to HEK293 cells, HOG-derived cells expressing IDH1R132H-V5 alone also showed elevated levels of $2 \mathrm{HG}$ and co-expression of IDH1-R132H-V5/ F-CIC significantly reduced the $2 \mathrm{HG}$ levels. Even so, co-expression of IDH1$\mathrm{R} 132 \mathrm{H}-\mathrm{V} 5$ and F-CIC-R1515H resulted in increased $2 \mathrm{HG}$ compared to $\mathrm{HOG}$ cells co-expressing either wild type F-CIC or mutant F-CIC-R201W, consistent with the HEK results. HOG cells differ from HEK cells in several ways, and so this level of concordance is likely reflective of underlying biology, not technical artifact.

The levels of ACLY/pACLY modulate tumourigenicity in gliomas [20]. Increased abundance of ACLY and pACLY was also associated with proliferation in other types of aggressive cancers [40, 42, 46-48]. In glioma cells, increased pACLY was observed in pseudopodia of U87 glioblastoma cells and was associated with increased clonogenicity and cell migration [20]. In other studies, inhibition or reduction of ACLY suppressed cell proliferation $[38,49,50]$. Consistent with these findings, we assigned a novel function to mutant CIC-S in reducing ACLY/pACLY levels in our cell lines and in human tumour samples and correlated this reduction with reduced clonogenicity in vitro.

Whether mutations in IDH1 promote or inhibit cell proliferation and survival depends on the tumor site. While mutations in IDH genes in Acute Myeloid Leukemia have been associated with poor prognosis, the same mutations are considered as markers of improved prognosis in gliomas, indicating interactions with other proteins or the tumour environment may ultimately influence the role of IDH in tumour pathogenesis. While several studies of glioma patient samples $[51,52]$ found no correlation between IDH1 mutations and tumour invasiveness, another study [53] in a fibrosarcoma cell line with endogenous IDH1-R132C showed a requirement for mutant IDH1 protein for cell survival. Our study is in agreement with studies $[54,55]$ in glioma cell lines stably transfected with IDH1-R132H-V5, where reduced proliferation and cell migration in vitro and in vivo were reported. 
Our study showed for the first time a cooperative reduction in clonogenicity in cells co-expressing IDH1$\mathrm{R} 132 \mathrm{H}$ and mutant CIC proteins. A cooperative phenotype of lower proliferation driven by co-expression of mutant IDH1 and mutant CIC proteins in HEK293 and HOG stable cell lines is at least in part in agreement with several important observations in gliomas: (a) Glioma patients with IDH1-R132H or IDH2-R172K had slower tumour progression, longer survival and better response to radiation or Temozolomide treatment $[55,56]$; (b) Mutations in CIC were almost always observed in $1 \mathrm{p} 19 \mathrm{q}$ co-deleted ODG and patients with this type of ODG had slower tumour growth and longer overall survival compared to ODG without co-deletion $[2,4]$; (c) Transgenic mouse models expressing IDH1-R132H in brain exhibit hemorrhage, reduced proliferation and increased apoptosis and failed to spontaneously develop brain tumors [57]; (d) Attempts to culture ODG cells in vitro failed to grow ODG lines that harbor both IDH1 and CIC mutations [44, 58].

Although the reduced clonogenicity and cell proliferation of IDH1 and CIC mutations alone or in combination are in agreement with the slow growing nature of ODG with $1 \mathrm{p} 19 \mathrm{q}$ co-deletions, the selective advantage that slow growth confers on malignant cells is unclear. One explanation may be that other oncogenic proteins or pathways may drive or be permissive for tumour progression of ODGs initially. In line with this hypothesis, a recent study by Killela and colleagues [9] identified recurrent mutations in the C228T or C250T positions of TERT promoters in ODGs with $1 \mathrm{p} 19 \mathrm{q}$ deletions and suggested that these mutations may promote a self-renewal capability in these tumours. It is possible that the mutations in IDH1 and CIC may in fact be moderately deleterious and reduce clonogenicity but may provide other timely survival advantages under certain conditions during oligodendroglioma disease progression.

\section{MATERIALS AND METHODS}

\section{Cell culture, cell lysate preparations and western blot analysis}

HEK293A, MDA-MB-231, HOG, and HeLa cell lines were cultured in DMEM (Invitrogen) supplemented with $10 \%$ (v/v) heat inactivated FBS (Invitrogen). C643 and H522 cell lines were cultured in RPMI (Invitrogen) supplemented with $10 \%(\mathrm{v} / \mathrm{v})$ heat inactivated FBS. Stable cell lines derived from HEK293A or HOG were cultured in DMEM $+10 \%$ FBS with selection (G418 and zeocin). Unless otherwise indicated, experiments with stable cell lines were always performed between passages 8-14. Cells were cultured without selection for at least two passages before experiments. Cell culturing was performed in a humidified, $37^{\circ} \mathrm{C}, 5 \% \mathrm{CO} 2$ incubator. Cell lysate preparations, cell fractionations and western blot analysis were performed using standard protocols and are described in detail in the Supplementary data S1.

\section{Immunoprecipitation, mass spectrometry and identification of candidate interaction partners}

For CIC immunoprecipitation, myc-CIC-S or rabbit/mouse IgG (control) antibody-bound beads were prepared by incubating anti-CIC antibody, anti-myc antibody, normal rabbit-IgG, or mouse-IgG with protein $\mathrm{G}$ agarose beads (Roche) in IP buffer (20mM Tris- $\mathrm{HCl}$ $\mathrm{pH} 7.5,150 \mathrm{mM} \mathrm{NaCl}, 1 \mathrm{mM}$ EDTA with $1 \mathrm{X}$ complete protease inhibitor from Roche) at $4{ }^{\circ} \mathrm{C}$ overnight. Cell lysates were first pre-cleared with Sepharose 4B beads (Sigma) at $4^{\circ} \mathrm{C}$ for 1 hour and the lysates were immunoprecipitated with the prepared protein-G beads at $4^{\circ} \mathrm{C}$ for 4 hours. The captured proteins and protein complexes were released by boiling the beads in $2 \mathrm{X}$ LDS Sample Buffer (Invitrogen) at $95^{\circ} \mathrm{C}$ for 5 minutes or $2 \mathrm{X}$ SDS sample buffer (117mM Tris-Cl pH6.8, 4\% SDS, $8 \%$ glycerol, $0.01 \%$ bromophenol blue, $200 \mathrm{mM}$ DTT) at $98^{\circ} \mathrm{C}$ for 10 minutes (see supplementary for details). For immunoprecipitations using FLAG epitopes, complexes in the pre-cleared lysate were captured by anti-FLAG M2 Affinity agarose (Sigma) for 2 hours at $4{ }^{\circ} \mathrm{C}$. Captured proteins and complexes were eluted by two rounds of FLAG-peptide competition (400ug/mL FLAG peptide, $50 \mathrm{mM}$ ammonium bicarbonate) for 30 minutes at $4{ }^{\circ} \mathrm{C}$.

\section{Serum free cell culturing}

Cells were first plated in DMEM $+10 \%$ FBS. The following day, media were replaced with Neurocult proliferation media supplemented with cytokines (Stem Cell Technologies) and growth factors EGF, FGF $(20 \mu \mathrm{g} /$ $\mathrm{ml}$ each; Peprotech) and Heparin (0.1\%; Stem Cell Technologies) and cells were grown for the time periods indicated. For caspase inhibition assays, cells were grown with or without the pan caspase inhibitor zVAD-FMK (BD Biosciences)

\section{Clonogenic and crystal violet cell proliferation assays}

Stable cell lines were plated at $1 \times 10^{4}$ cells per well in a 6-well plate. Cells were grown in ODG media for up to 2 weeks. Colonies were fixed with $4 \%$ paraformaldehyde and stained with $10 \%$ crystal violet. Images of colonies were captured using a Bio-Rad imaging system. Retained crystal violet stain was resolubilized in $1 \mathrm{ml} 10 \%$ acetic acid by rocking for $15 \mathrm{~min}$. Readings were taken at $\mathrm{A}_{590}$ using a plate reader (VersaMAX Microplate Reader). 


\section{Statistical analysis}

For multiple comparisons of western blot results, $2 \mathrm{HG} / 2 \mathrm{KG}$ levels and clonogenic crystal violet proliferation assays, one-way ANOVA with Dunnett's post-test were performed using Prism 6.0 Software (GraphPad Software Inc.).

For further descriptions of Materials and Methods, please see the Supplementary Materials and Methods.

\section{ACKNOWLEGEMENTS}

We thank the DNA sequencing, library construction, and biospecimen cores at the BC Cancer Agency Genome Sciences Centre for technical support. We thank Robyn Roscoe for expert Project Management support. The authors thank Chandra Lebovitz and Dr. Jill Mwenifumbo for helpful edits and comments on the manuscript. We thank Drs. Carol MacKintosh (University of Dundee, Scotland, UK) and Huda Y. Zoghbi (Howard Hughes Medical Institute, Houston, Texas) for providing us with CIC constructs. We thank Dr. G. Dawson (The University of Chicago, Illinois, USA) for providing us the HOG glioma cell line. We thank Drs. Andreas von Deimling and Joerg Balss (DKFZ - German Cancer Research Center, Heidelberg, Germany) for providing us with HGDH enzyme for $2 \mathrm{HG}$ enzymatic assays. MAM acknowledges the support of the Canada Research Chairs program and the BC Cancer Foundation, and is especially grateful to Ms. Donna Anderson for her generosity in supporting this project. SMG gratefully acknowledges support from CIHR MOP-78882 and a CIHR New Investigator award. GBM acknowledges support from the BC Cancer Foundation. JGC is supported by the Alberta Cancer Foundation, the Terry Fox Research Institute and Foundation, and the generosity of the family of Clark H. Smith. SY acknowledges generous support from BrainCareBC and a VCHRI Mentored Clinician Scientist Award

\section{Author contributions}

MAM and SC conceived and designed the experiments; SYC, CY, KCY, MF, NEG, JS, and SC performed the experiments. $\mathrm{VC}$ and $\mathrm{AM}$ provided the technical support for mass spectrometry analyses. MB and $\mathrm{JAC}$ provided tools and techniques for growing ODG lines. SC analyzed and interpreted the data. MAM and SC wrote the manuscript. JAC, JGC, SMG, GM, SY and MAM provided ideas, discussion and critically reviewed the manuscript.

\section{Conflict of interests}

The authors declare that they have no conflict of interest.

\section{REFERENCES}

1. Bralten LB, Nouwens S, Kockx C, Erdem L, Hoogenraad CC, Kros JM, Moorhouse MJ, Sillevis Smitt PA, van der Spek P, van Ijcken W, Stubbs A, French PJ. Absence of Common Somatic Alterations in Genes on $1 p$ and $19 q$ in Oligodendrogliomas. PLoS ONE 2011; 6(7):e22000.

2. Yip S, Butterfield YS, Morozova O, Chittaranjan S, Blough MD, An J, Birol I, Chesnelong C, Chiu R, Chuah E, Corbett R, Docking R, Firme M, Hirst M, Jackman S, Karsan A et al. Concurrent CIC mutations, IDH mutations, and $1 \mathrm{p} / 19 \mathrm{q}$ loss distinguish oligodendrogliomas from other cancers. J. Pathol. 2012; 226(1):7-16.

3. Cairncross JG, Ueki K, Zlatescu MC, Lisle DK, Finkelstein DM, Hammond RR, Silver JS, Stark PC, Macdonald DR, Ino Y, Ramsay DA, Louis DN. Specific genetic predictors of chemotherapeutic response and survival in patients with anaplastic oligodendrogliomas. J. Natl. Cancer Inst. 1998; 90(19):1473-1479.

4. Ino Y, Betensky RA, Zlatescu MC, Sasaki H, Macdonald DR, Stemmer-Rachamimov AO, Ramsay DA, Cairncross JG, Louis DN. Molecular Subtypes of Anaplastic Oligodendroglioma Implications for Patient Management at Diagnosis. Clin. Cancer Res. 2001; 7(4):839-845.

5. Bettegowda C, Agrawal N, Jiao Y, Sausen M, Wood LD, Hruban RH, Rodriguez FJ, Cahill DP, McLendon R, Riggins G, Velculescu VE, Oba-Shinjo SM, Marie SKN, Vogelstein B, Bigner D, Yan H et al. Mutations in CIC and FUBP1 contribute to human oligodendroglioma. Science 2011; 333(6048):1453-1455.

6. Eisenreich S, Abou-El-Ardat K, Szafranski K, Campos Valenzuela JA, Rump A, Nigro JM, Bjerkvig R, Gerlach E-M, Hackmann K, Schröck E, Krex D, Kaderali L, Schackert G, Platzer M, Klink B. Novel CIC Point Mutations and an Exon-Spanning, Homozygous Deletion Identified in Oligodendroglial Tumors by a Comprehensive Genomic Approach Including Transcriptome Sequencing. PLoS ONE 2013; 8(9):e76623.

7. Jiao Y, Killela PJ, Reitman ZJ, Rasheed AB, Heaphy CM, de Wilde RF, Rodriguez FJ, Rosemberg S, Oba-Shinjo SM, Nagahashi Marie SK, Bettegowda C, Agrawal N, Lipp E, Pirozzi C, Lopez G, He Y et al. Frequent ATRX, CIC, FUBP1 and IDH1 mutations refine the classification of malignant gliomas. Oncotarget 2012; 3(7):709-722.

8. Sahm F, Koelsche C, Meyer J, Pusch S, Lindenberg K, Mueller W, Herold-Mende C, von Deimling A, Hartmann C. CIC and FUBP1 mutations in oligodendrogliomas, oligoastrocytomas and astrocytomas. Acta Neuropathol. (Berl.) 2012; 123(6):853-860. 
9. Killela PJ, Reitman ZJ, Jiao Y, Bettegowda C, Agrawal N, Diaz LA Jr, Friedman AH, Friedman H, Gallia GL, Giovanella BC, Grollman AP, He T-C, He Y, Hruban RH, Jallo GI, Mandahl N et al. TERT promoter mutations occur frequently in gliomas and a subset of tumors derived from cells with low rates of self-renewal. Proc. Natl. Acad. Sci. U. S. A. 2013; 110(15):6021-6026.

10. Lam YC, Bowman AB, Jafar-Nejad P, Lim J, Richman R, Fryer JD, Hyun ED, Duvick LA, Orr HT, Botas J, Zoghbi HY. ATAXIN-1 interacts with the repressor Capicua in its native complex to cause SCA1 neuropathology. Cell 2006; 127(7):1335-1347.

11. Lee C-J, Chan W-I, Cheung M, Cheng Y-C, Appleby VJ, Orme AT, Scotting PJ. CIC, a member of a novel subfamily of the HMG-box superfamily, is transiently expressed in developing granule neurons. Brain Res. Mol. Brain Res. 2002; 106(1-2):151-156.

12. Jiménez G, Guichet A, Ephrussi A, Casanova J. Relief of gene repression by torso RTK signaling: role of capicua in Drosophila terminal and dorsoventral patterning. Genes Dev. 2000; 14(2):224-231.

13. Goff DJ, Nilson LA, Morisato D. Establishment of dorsalventral polarity of the Drosophila egg requires capicua action in ovarian follicle cells. Dev. Camb. Engl. 2001; 128(22):4553-4562.

14. Roch F, Jiménez G, Casanova J. EGFR signalling inhibits Capicua-dependent repression during specification of Drosophila wing veins. Dev. Camb. Engl. 2002; 129(4):993-1002.

15. Tseng A-SK, Tapon N, Kanda H, Cigizoglu S, Edelmann L, Pellock B, White K, Hariharan IK. Capicua regulates cell proliferation downstream of the receptor tyrosine kinase/ras signaling pathway. Curr. Biol. CB 2007; 17(8):728-733.

16. Yoshimoto M, Graham C, Chilton-MacNeill S, Lee E, Shago M, Squire J, Zielenska M, Somers GR. Detailed cytogenetic and array analysis of pediatric primitive sarcomas reveals a recurrent CIC-DUX4 fusion gene event. Cancer Genet. Cytogenet. 2009; 195(1):1-11.

17. Kawamura-Saito M, Yamazaki Y, Kaneko K, Kawaguchi N, Kanda H, Mukai H, Gotoh T, Motoi T, Fukayama M, Aburatani H, Takizawa T, Nakamura T. Fusion between CIC and DUX4 up-regulates PEA3 family genes in Ewinglike sarcomas with $\mathrm{t}(4 ; 19)(\mathrm{q} 35 ; \mathrm{q} 13)$ translocation. Hum. Mol. Genet. 2006; 15(13):2125-2137.

18. Dissanayake K, Toth R, Blakey J, Olsson O, Campbell DG, Prescott AR, MacKintosh C. ERK/p90(RSK)/14-3-3 signalling has an impact on expression of PEA3 Ets transcription factors via the transcriptional repressor capicúa. Biochem. J. 2011; 433(3):515-525.

19. Kim E, Lu H-C, Zoghbi HY, Song J-J. Structural basis of protein complex formation and reconfiguration by polyglutamine disease protein Ataxin-1 and Capicua. Genes Dev. 2013; 27(6):590-595.

20. Beckner ME, Fellows-Mayle W, Zhang Z, Agostino NR,
Kant JA, Day BW, Pollack IF. Identification of ATP citrate lyase as a positive regulator of glycolytic function in glioblastomas. Int. J. Cancer J. Int. Cancer 2010; 126(10):2282-2295.

21. Oudard S, Boitier E, Miccoli L, Rousset S, Dutrillaux B, Poupon MF. Gliomas are driven by glycolysis: putative roles of hexokinase, oxidative phosphorylation and mitochondrial ultrastructure. Anticancer Res. 1997; 17(3C):1903-1911.

22. Wise DR, Ward PS, Shay JES, Cross JR, Gruber JJ, Sachdeva UM, Platt JM, DeMatteo RG, Simon MC, Thompson CB. Hypoxia promotes isocitrate dehydrogenase-dependent carboxylation of $\alpha$-ketoglutarate to citrate to support cell growth and viability. Proc. Natl. Acad. Sci. 2011; 108(49):19611-19616.

23. Costello LC, Franklin RB. A review of the important central role of altered citrate metabolism during the process of stem cell differentiation. J. Regen. Med. Tissue Eng. 2013; 2(1):1.

24. Icard P, Poulain L, Lincet H. Understanding the central role of citrate in the metabolism of cancer cells. Biochim. Biophys. Acta 2012; 1825(1):111-116.

25. Wellen KE, Hatzivassiliou G, Sachdeva UM, Bui TV, Cross JR, Thompson CB. ATP-Citrate Lyase Links Cellular Metabolism to Histone Acetylation. Science 2009; 324(5930):1076-1080.

26. Dang L, White DW, Gross S, Bennett BD, Bittinger MA, Driggers EM, Fantin VR, Jang HG, Jin S, Keenan MC, Marks KM, Prins RM, Ward PS, Yen KE, Liau LM, Rabinowitz JD et al. Cancer-associated IDH1 mutations produce 2-hydroxyglutarate. Nature 2009; 462(7274):739.

27. Ward PS, Cross JR, Lu C, Weigert O, Abel-Wahab O, Levine RL, Weinstock DM, Sharp KA, Thompson CB. Identification of additional IDH mutations associated with oncometabolite R(-)-2-hydroxyglutarate production. Oncogene 2012; 31(19):2491-2498.

28. Losman J-A, Looper RE, Koivunen P, Lee S, Schneider RK, McMahon C, Cowley GS, Root DE, Ebert BL, Kaelin WG. (R)-2-Hydroxyglutarate Is Sufficient to Promote Leukemogenesis and Its Effects Are Reversible. Science 2013; 339(6127):1621-1625.

29. Turcan S, Rohle D, Goenka A, Walsh LA, Fang F, Yilmaz E, Campos C, Fabius AWM, Lu C, Ward PS, Thompson CB, Kaufman A, Guryanova O, Levine R, Heguy A, Viale A et al. IDH1 mutation is sufficient to establish the glioma hypermethylator phenotype. Nature 2012; 483(7390):479483.

30. Kelly JJP, Blough MD, Stechishin ODM, Chan JAW, Beauchamp D, Perizzolo M, Demetrick DJ, Steele L, Auer RN, Hader WJ, Westgate M, Parney IF, Jenkins $\mathrm{R}$, Cairncross JG, Weiss S. Oligodendroglioma cell lines containing $\mathrm{t}(1 ; 19)(\mathrm{q} 10 ; \mathrm{p} 10)$. Neuro-Oncol. 2010; 12(7):745-755.

31. Lynn BD, Turley EA, Nagy JI. Subcellular distribution, 
calmodulin interaction, and mitochondrial association of the hyaluronan-binding protein RHAMM in rat brain. J. Neurosci. Res. 2001; 65(1):6-16.

32. Gilquin B, Taillebourg E, Cherradi N, Hubstenberger A, Gay O, Merle N, Assard N, Fauvarque M-O, Tomohiro S, Kuge O, Baudier J. The AAA+ ATPase ATAD3A controls mitochondrial dynamics at the interface of the inner and outer membranes. Mol. Cell. Biol. 2010; 30(8):1984-1996.

33. Shaw G, Morse S, Ararat M, Graham FL. Preferential transformation of human neuronal cells by human adenoviruses and the origin of HEK 293 cells. FASEB J. 2002; 16(8):869-871.

34. Post GR, Dawson G. Characterization of a cell line derived from a human oligodendroglioma. Mol. Chem. Neuropathol. Spons. Int. Soc. Neurochem. World Fed. Neurol. Res. Groups Neurochem. Cerebrospinal Fluid 1992; 16(3):303-317.

35. Long PM, Tighe SW, Driscoll HE, Moffett JR, Namboodiri AMA, Viapiano MS, Lawler SE, Jaworski DM. Acetate Supplementation Induces Growth Arrest of NG2/PDGFR $\alpha$ Positive Oligodendroglioma-Derived Tumor-Initiating Cells. PLoS ONE 2013; 8(11):e80714.

36. Reitman ZJ, Jin G, Karoly ED, Spasojevic I, Yang J, Kinzler KW, He Y, Bigner DD, Vogelstein B, Yan H. Profiling the effects of isocitrate dehydrogenase 1 and 2 mutations on the cellular metabolome. Proc. Natl. Acad. Sci. 2011; 108(8):3270-3275.

37. Balss J, Pusch S, Beck A-C, Herold-Mende C, Krämer A, Thiede C, Buckel W, Langhans C-D, Okun JG, von Deimling A. Enzymatic assay for quantitative analysis of (D)-2-hydroxyglutarate. Acta Neuropathol. (Berl.) 2012; 124(6):883-891.

38. Hanai J, Doro N, Sasaki AT, Kobayashi S, Cantley LC, Seth P, Sukhatme VP. Inhibition of lung cancer growth: ATP citrate lyase knockdown and statin treatment leads to dual blockade of mitogen-activated protein kinase (MAPK) and phosphatidylinositol-3-kinase (PI3K)/AKT pathways. J. Cell. Physiol. 2012; 227(4):1709-1720.

39. Potapova IA, El-Maghrabi MR, Doronin SV, Benjamin WB. Phosphorylation of recombinant human ATP:citrate lyase by cAMP-dependent protein kinase abolishes homotropic allosteric regulation of the enzyme by citrate and increases the enzyme activity. Allosteric activation of ATP:citrate lyase by phosphorylated sugars. Biochemistry (Mosc.) 2000; 39(5):1169-1179.

40. Zaidi N, Swinnen JV, Smans K. ATP-citrate lyase: a key player in cancer metabolism. Cancer Res. 2012; 72(15):3709-3714.

41. Sun T, Hayakawa K, Bateman KS, Fraser ME. Identification of the Citrate-binding Site of Human ATP-Citrate Lyase Using X-ray Crystallography. J. Biol. Chem. 2010; 285(35):27418-27428.

42. Migita $T$, Narita $T$, Nomura $K$, Miyagi E, Inazuka $F$, Matsuura M, Ushijima M, Mashima T, Seimiya H, Satoh Y,
Okumura S, Nakagawa K, Ishikawa Y. ATP Citrate Lyase: Activation and Therapeutic Implications in Non-Small Cell Lung Cancer. Cancer Res. 2008; 68(20):8547-8554.

43. Chu KY, Lin Y, Hendel A, Kulpa JE, Brownsey RW, Johnson JD. ATP-Citrate Lyase Reduction Mediates Palmitate-induced Apoptosis in Pancreatic Beta Cells. J. Biol. Chem. 2010; 285(42):32606-32615.

44. Klink B, Miletic H, Stieber D, Huszthy PC, Valenzuela JAC, Balss J, Wang J, Schubert M, Sakariassen PØ, Sundstrøm T, Torsvik A, Aarhus M, Mahesparan R, von Deimling A, Kaderali L, Niclou SP et al. A Novel, Diffusely Infiltrative Xenograft Model of Human Anaplastic Oligodendroglioma with Mutations in FUBP1, CIC, and IDH1. PLoS ONE 2013; 8(3):e59773.

45. Luchman HA, Stechishin OD, Dang NH, Blough MD, Chesnelong C, Kelly JJ, Nguyen SA, Chan JA, Weljie AM, Cairncross JG, Weiss S. An in vivo patient-derived model of endogenous IDH1-mutant glioma. Neuro-Oncol. 2012; 14(2):184-191.

46. Turyn J, Schlichtholz B, Dettlaff-Pokora A, Presler M, Goyke E, Matuszewski M, Kmieć Z, Krajka K, Swierczynski J. Increased activity of glycerol 3-phosphate dehydrogenase and other lipogenic enzymes in human bladder cancer. Horm. Metab. Res. Horm. Stoffwechselforschung Horm. Métabolisme 2003; 35(10):565-569.

47. Varis A, Wolf M, Monni O, Vakkari M-L, Kokkola A, Moskaluk C, Frierson H Jr, Powell SM, Knuutila S, Kallioniemi A, El-Rifai W. Targets of gene amplification and overexpression at $17 \mathrm{q}$ in gastric cancer. Cancer Res. 2002; 62(9):2625-2629.

48. Yancy HF, Mason JA, Peters S, Thompson CE, Littleton GK, Jett M, Day AA. Metastatic progression and gene expression between breast cancer cell lines from African American and Caucasian women. J. Carcinog. 2007; 6:8.

49. Bauer DE, Hatzivassiliou G, Zhao F, Andreadis C, Thompson CB. ATP citrate lyase is an important component of cell growth and transformation. Oncogene 2005; 24(41):6314-6322.

50. Hatzivassiliou G, Zhao F, Bauer DE, Andreadis C, Shaw AN, Dhanak D, Hingorani SR, Tuveson DA, Thompson CB. ATP citrate lyase inhibition can suppress tumor cell growth. Cancer Cell 2005; 8(4):311-321.

51. Gozé C, Bezzina C, Gozé E, Rigau V, Maudelonde T, Bauchet L, Duffau H. 1P19Q loss but not IDH1 mutations influences WHO grade II gliomas spontaneous growth. J. Neurooncol. 2012; 108(1):69-75.

52. Preusser M, Hoeftberger R, Woehrer A, Gelpi E, Kouwenhoven M, Kros JM, Sanson M, Idbaih A, Brandes AA, Heinzl H, Gorlia T, Hainfellner JA, van den Bent M. Prognostic value of Ki67 index in anaplastic oligodendroglial tumours--a translational study of the European Organization for Research and Treatment of Cancer Brain Tumor Group. Histopathology 2012; 60(6):885-894. 
53. Jin G, Pirozzi CJ, Chen LH, Lopez GY, Duncan CG, Feng J, Spasojevic I, Bigner DD, He Y, Yan H. Mutant IDH1 is required for IDH1 mutated tumor cell growth. Oncotarget 2012; 3(8):774-782.

54. Bralten LBC, Kloosterhof NK, Balvers R, Sacchetti A, Lapre L, Lamfers M, Leenstra S, de Jonge H, Kros JM, Jansen EEW, Struys EA, Jakobs C, Salomons GS, Diks SH, Peppelenbosch M, Kremer A et al. IDH1 R132H decreases proliferation of glioma cell lines in vitro and in vivo. Ann. Neurol. 2011; 69(3):455-463.

55. Li S, Chou AP, Chen W, Chen R, Deng Y, Phillips HS, Selfridge J, Zurayk M, Lou JJ, Everson RG, Wu K-C, Faull KF, Cloughesy T, Liau LM, Lai A. Overexpression of isocitrate dehydrogenase mutant proteins renders glioma cells more sensitive to radiation. Neuro-Oncol. 2013; 15(1):57-68.

56. Van den Bent MJ, Dubbink HJ, Marie Y, Brandes AA, Taphoorn MJB, Wesseling P, Frenay M, Tijssen CC, Lacombe D, Idbaih A, van Marion R, Kros JM, Dinjens WNM, Gorlia T, Sanson M. IDH1 and IDH2 mutations are prognostic but not predictive for outcome in anaplastic oligodendroglial tumors: a report of the European Organization for Research and Treatment of Cancer Brain Tumor Group. Clin. Cancer Res. Off. J. Am. Assoc. Cancer Res. 2010; 16(5):1597-1604.

57. Sasaki M, Knobbe CB, Itsumi M, Elia AJ, Harris IS, Chio IIC, Cairns RA, McCracken S, Wakeham A, Haight J, Ten AY, Snow B, Ueda T, Inoue S, Yamamoto K, Ko M et al. D-2-hydroxyglutarate produced by mutant IDH1 perturbs collagen maturation and basement membrane function. Genes Dev. 2012; 26(18):2038-2049.

58. Piaskowski S, Bienkowski M, Stoczynska-Fidelus E, Stawski R, Sieruta M, Szybka M, Papierz W, Wolanczyk M, Jaskolski DJ, Liberski PP, Rieske P. Glioma cells showing IDH1 mutation cannot be propagated in standard cell culture conditions. Br. J. Cancer 2011; 104(6):968-970. 